\title{
New Pathways for Hydropower: Getting Hydropower Built-What Does It Take?
}

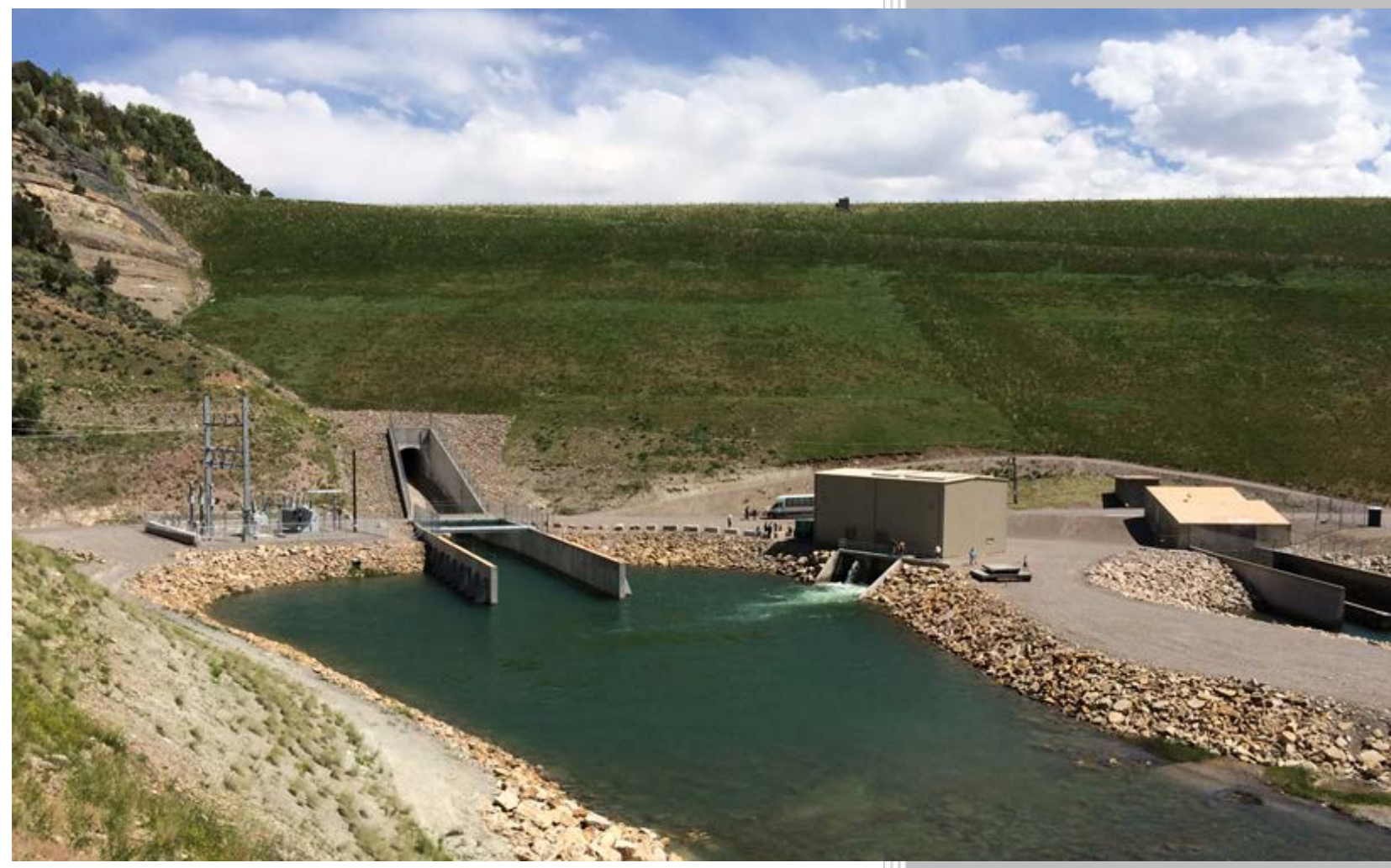

Lead Authors:

Norm Bishop Deborah Linke

Editor: Carl Vansant

Contributing Authors: Chuck Alsberg Jay Anders Ali Grovue Sarah Hill-Nelson

This document has been reviewed and is determined to be APPROVED FOR PUBLIC RELEASE.

Name/Title: Tammy Claiborne/ORNL TIO

Date: $\underline{03 / 29 / 2021}$
Kurt Johnson Brennan Smith Dave Youlen Kevin Young

January 2015 


\section{DOCUMENT AVAILABILITY}

Reports produced after January 1, 1996, are generally available free via US Department of Energy (DOE) SciTech Connect.

Website http://www.osti.gov/scitech/

Reports produced before January 1, 1996, may be purchased by members of the public from the following source:

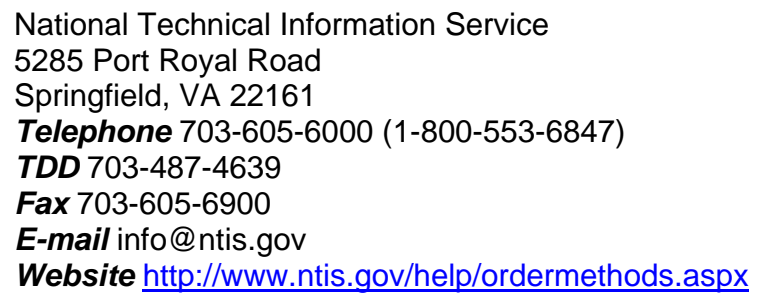

Reports are available to DOE employees, DOE contractors, Energy Technology Data Exchange representatives, and International Nuclear Information System representatives from the following source:

Office of Scientific and Technical Information

PO Box 62

Oak Ridge, TN 37831

Telephone 865-576-8401

Fax 865-576-5728

E-mail reports@osti.gov

Website http://www.osti.gov/contact.html

This report was prepared as an account of work sponsored by an agency of the United States Government. Neither the United States Government nor any agency thereof, nor any of their employees, makes any warranty, express or implied, or assumes any legal liability or responsibility for the accuracy, completeness, or usefulness of any information, apparatus, product, or process disclosed, or represents that its use would not infringe privately owned rights. Reference herein to any specific commercial product, process, or service by trade name, trademark, manufacturer, or otherwise, does not necessarily constitute or imply its endorsement, recommendation, or favoring by the United States Government or any agency thereof. The views and opinions of authors expressed herein do not necessarily state or reflect those of the United States Government or any agency thereof.

The cover photo shows the Tri-County Water Conservancy District's 8-MW hydropower complex, which was commissioned in 2014 at the U.S. Bureau of Reclamation's Ridgeway Dam. Photo courtesy of TriCounty Water Conservancy District. 
Environmental Sciences

Energy-Water Resource Systems Group

\section{New Pathways for Hydropower Development \\ What It Takes to Get Hydropower Built}

Date Published: October 2014

Prepared by

Hydro Research Foundation in cooperation with

Oak Ridge National Laboratory

Under Subcontract 4000126615

Prepared for

OAK RIDGE NATIONAL LABORATORY

Oak Ridge, Tennessee 37831-6283

managed by

UT-BATTELLE, LLC

for the

US DEPARTMENT OF ENERGY

under contract DE-AC05-00OR22725 



\section{Table of Contents}

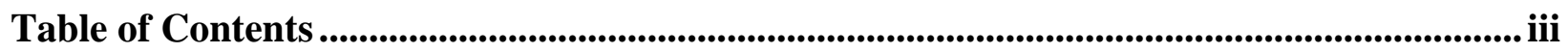

Executive Summary .................................................................................................................

Abbreviations, Acronyms, and Initialisms ............................................................................... vii

Introduction 1

Section 1. Background and Perspective......................................................................... 2

The Need for New Pathways to Feasibility ................................................................................ 2

Purpose and Scope..................................................................................................................... 2

Assessments of Hydropower Development Opportunities ..................................................................... 3

The Importance of Innovating Early in Project Development.................................................................... 4

Developer Types and Roles.......................................................................................................... 4

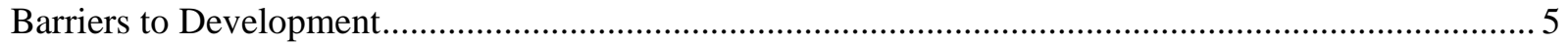

Section 2. Ideas and Solutions ................................................................................................. 7

Improved Tools for Siting, Pre-qualification, and Feasibility Determination ........................................ 10

Idea 1: Develop a website/portal enabling access to public information to help developers accelerate site assessment................................................................................................ 10

Idea 2 : Study a selected region/locale to assess opportunities for siting new smallhydropower installations .............................................................................................. 13

Idea 3: Develop improved tools for early project configuration and cost estimating ......................... 14

Idea 4: Enhance the DSIRE online database to include and highlight hydropower-related

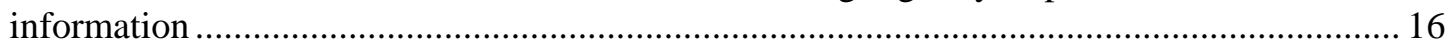

New and Improved Design Tools_Guidelines and Standards ............................................................. 17

Idea 5: Develop a guide for draft tube configuration .................................................................... 17

Idea 6: Develop design standards and models for siphon hydroelectric plants to support

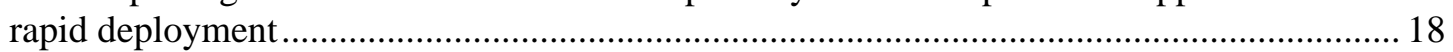

Idea 7: Develop design standards and best practices for the application of new penstock

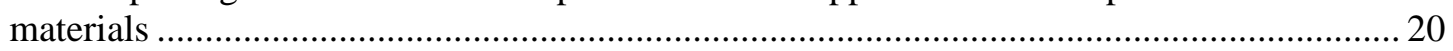

Idea 8: Develop a guideline for capital cost-saving "fit for purpose" project designs ........................ 21

Improved Access to Design-related Information—Online Toolboxes and Databases ..............................22

Idea 9 : Develop an online hydropower construction materials toolbox ..............................................22

Idea 10: Develop an online repository of information for gates and operators .................................. 24

Idea 11: Develop an online inventory of fish screens, bypass systems, lifts, and ladders ................. 25

Idea 12: Develop a procurement toolbox for hydropower equipment, components, and

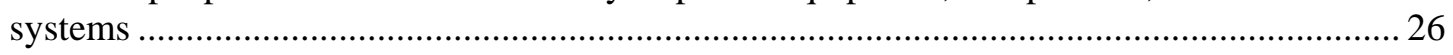

New Hydro-Specific Education, Training, and Outreach...................................................................... 28

Idea 13: Prepare and distribute white papers on new small-hydropower technology ………...............28

Idea 14: Develop a hydropower-specific core education curriculum for hydropower

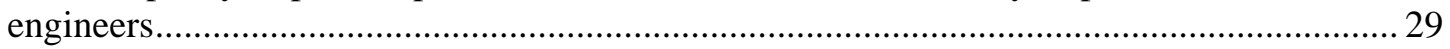

Idea 15: Develop a training course for small-hydropower operators .................................................. 30

Advanced and Improved Technology, Materials, and Manufacturing .................................................... 31

Idea 16: Expand the use of alternative and composite materials in hydropower plant

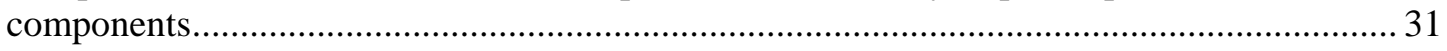

Idea 17: Develop strategies for smaller and reduced reinforced-concrete structures.......................... 33

Idea 18: Develop new turbine technology to reduce or eliminate civil construction ............................35

Idea 19: Accelerate three-dimensional printing of turbines and components ...................................... 36 
Idea 20: Establish specifications, criteria, and validation methods for fish-friendly turbines............ 38

Idea 21: Stimulate technology innovation relevant to new hydropower ...........................................40

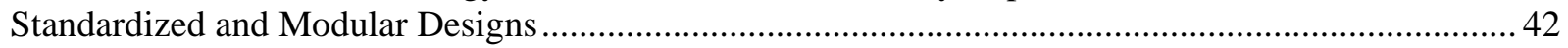

Idea 22: Develop standard designs for conduit hydropower ........................................................... 42

Idea 23: Develop standardized, factory-assembled small-hydropower equipment packages

with ancillary equipment mounted on skids to speed construction ..........................................43

Idea 24: Simplify project operations and maintenance by using modular components ..................... 44

Idea 25: Develop a library of three-dimensional drawings and configurations................................ 45

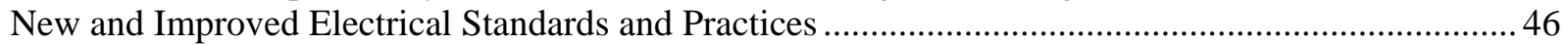

Idea 26: Develop standard electrical and control configurations for new hydropower plants ........... 46

Idea 27: Develop standard substation configurations....................................................................... 47

Idea 28: Develop small-hydropower standards for the National Electrical Code ............................. 48

Idea 29: Develop and promote standard interconnection methods and standards for smallhydropower and micro-hydropower installations.................................................................... 49

Idea 30: Explore expanded use of net metering in small-hydropower and micro-hydropower

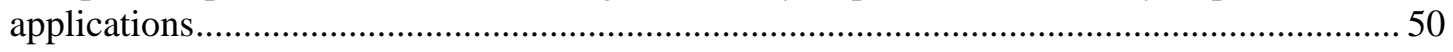

Tools for Commissioning, Operation, and Maintenance...................................................................... 51

Idea 31: Develop best- practices guidance for small-hydropower project commissioning and

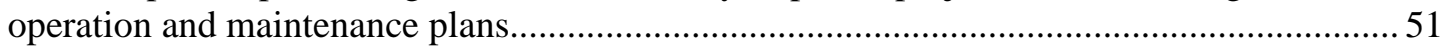

Appendix A Compilation of Best Practices Gathered During the Preparation of the Report ................................................................................................................................ 53

Appendix B Authors and Contributors to Report ..........................................................65 


\section{Executive Summary}

This report is part of the New Hydropower Innovation Collaborative (NHIC), a partnership between the Hydro Research Foundation and Oak Ridge National Laboratory (ORNL), with support from the U.S. Department of Energy Water Power Program. New hydropower presents a substantial opportunity for increased electric generation, improvements in grid security and stability, and increased economic development.

The purpose of the Collaborative is to identify technological innovations and innovative policy alternatives that will decrease the expense and time required to deploy new hydropower in the United States. These technological innovations are the subject of this report. Innovative policy alternatives are addressed in a separate policy alternative report. The NHIC also includes development of a web-based technology catalog containing project-specific and vendor and technology information that is useful to the new small-hydropower community.

This report identifies 31 technological ideas. Several of the ideas address the need to nurture hydropower-specific innovation and education. Although the focus of this report is new small hydropower, many of the ideas presented herein are applicable to hydropower development in general. The ideas are grouped into eight categories:

- Improved Tools for Siting, Prequalification, and Feasibility Determination

- New and Improved Design Tools - Guidelines and Standards

- Improved Access to Design-related Information-Online Toolboxes and Databases

- New Hydropower-Specific Education, Training, and Outreach

- Advanced and Improved Technology, Materials, and Manufacturing

- Standardized and Modular Designs

- New and Improved Electrical Standards and Practices

- Tools for Commissioning, Operation, and Maintenance

The ideas in this report, once implemented, validated, and disseminated, will reduce deployment cost and time through efficient designs, manufacturing, permitting and licensing, installation, commissioning, operations, and maintenance.

This report is published by Oak Ridge National Laboratory. ORNL does so to enable the technical insights of small hydropower developers to be cataloged and disseminated. However, the report ideas and recommendations are fundamentally those of the New Hydropower Innovation Collaborative participants. As such, the ideas and recommendations should not be interpreted guidance or intent by ORNL or the Department of Energy. The ideas and recommendations should be assimilated by all stakeholders in hydropower development so that each can develop more collaborative and robust approaches to achieve beneficial outcomes. 


\section{Abbreviations, Acronyms, and Initialisms}

ACI American Concrete Institute

AISC American Institute of Steel Construction

ASCE American Society of Civil Engineers

ASME American Society of Mechanical Engineers

ASTM American Society for Testing and Materials

AWWA American Water Works Association

DOE Department of Energy

DOI Department of Interior

DSIRE Database of State Incentives for Renewables and Efficiency

EPC engineer, procure, construct

FERC Federal Energy Regulatory Commission

GIS geographic information system

GW gigawatt

GWh gigawatt hour

IEEE Institute of Electrical and Electronic Engineers

kW kilowatt

MOU Memorandum of Understanding

MW megawatt

NGO nongovernmental organization

NSD new stream-reach development

ORNL Oak Ridge National Laboratory

PPA power purchase agreement 


$\begin{array}{ll}\text { REC } & \text { renewable energy credit } \\ \text { Reclamation } & \text { US Bureau of Reclamation } \\ \text { TVA } & \text { Tennessee Valley Authority } \\ \text { TWh } & \text { terawatt hour } \\ \text { USACE } & \text { US Army Corps of Engineers (also the Corps) } \\ \text { USGS } & \text { United States Geological Survey }\end{array}$




\section{Introduction}

Recent assessments suggest that much more hydropower - many thousands of megawatts-could be developed to increase the US electricity supply. However, there are barriers to that development that have proved to be difficult to overcome and continue to restrain development.

This report addresses the development of new small hydropower projects and technological and developmental innovations that are crucial to move beyond the barriers that are preventing development. Recent resource assessments by the US Department of Energy (DOE) have identified substantial undeveloped hydropower opportunities. With few exceptions, these opportunities range in capability from a few kilowatts (kW) to a few megawatts (MW).

This report is published by Oak Ridge National Laboratory. ORNL does so to enable the technical insights of small hydropower developers to be cataloged and disseminated. However, the report ideas and recommendations are fundamentally those of the New Hydropower Innovation Collaborative participants. As such, the ideas and recommendations should not be interpreted guidance or intent by ORNL or the Department of Energy. The ideas and recommendations should be assimilated by all stakeholders in hydropower development so that each can develop more collaborative and robust approaches to achieve beneficial outcomes.

This report is the result of a collaboration of experts with diverse perspectives and a wealth of experience in designing, developing, owning, and operating small hydropower facilities. These experts met in Golden, Colorado, in December 2013 to put forth innovative ideas about accelerating the development of small hydropower projects. Innovations put forth by these experts can yield more than just technology advancements. Innovation is possible in all phases of project development, from concept to commissioning to operations and maintenance. These innovative ideas were refined and organized in subsequent collaborations among these experts to produce this final version of the report.

This report is not prescriptive; nor is it a handbook on how to develop small-hydropower projects, although Appendix A does capture some current proven development best practices put forth by the authors. Rather, this report is an idea book-a compilation of ideas from knowledgeable individuals about which technology approaches, practices, and prospective new tools or developments could help bring additional small-hydropower projects from the realm of ideas to reality. The report does identify technology advancements, but it also suggests prospective ways of mitigating the risks of small hydropower development and reducing the timelines and costs of deployment. Finally, the report highlights opportunities for broad-based industry and government support to encourage implementation of these concepts and accelerate development. 


\section{Section 1. Background and Perspective}

\section{The Need for New Pathways to Feasibility}

Existing hydropower plants, many of which have been in service for 50 to 100 years, are valuable and proven generating assets through multiple eras and operational regimes.

Despite this success, the pace of new hydropower development has slowed relative to historical growth — only a modest amount of hydropower development is progressing. ${ }^{1}$ As a result of multiple economic and regulatory restraints, sites that would otherwise provide low-impact, sustainable energy production are not progressing from concept to commissioning.

Recent assessments of the hydropower resources in the United States suggest that as much as twice the current inventory of operating hydropower-about 90,000 MW-might realistically be developable. ${ }^{2}$ Although some of the report authors believe this figure is an overestimate, all believe there is opportunity for a substantial increase in total hydropower development. These assessments also indicate that many new hydropower facilities in the United States will be kilowatt and megawatt scale rather than gigawatt scale. ${ }^{3}$ However, significant new development in this size range is contingent on reductions in construction costs, sufficiency and security of revenue streams, and improvements in the efficiency of licensing for small hydropower. Although incremental advancements in powertrain technology will provide some cost reduction, innovations in project design, construction, and balance-of-plant equipment and structures will be as important in accelerating deployment.

The addition of new small-hydropower facilities to existing dams and other civil infrastructure is beneficial development, providing domestic energy production that enhances national energy security. Hydropower facilities make minimal contributions to air pollution, are long-lived, and respond quickly grid stabilization needs. Hydropower projects also reduce overall electricity cost volatility and uncertainty because most of the life-cycle costs are incurred at the time of construction rather than as fuel expenses. New small-hydropower facilities can be interconnected with local electric power distribution systems, avoiding the need for expensive and uncertain transmission asset development.

\section{Purpose and Scope}

This report explores innovations in the development of new small-hydropower projects from concept to commissioning and beyond. Its ultimate goal is to suggest new technology pathways that will reduce the cost of development and enable potential sites to become feasible and commissioned sites. More specifically, the working objectives of this report are threefold:

\footnotetext{
${ }^{1}$ The bulk of the existing US hydropower capacity was built during the 20th century. From the earliest commercialization of electricity in the 1880s, hydropower was a key supplier of electricity in the United States, supplying nearly half of all electricity during the early part of the 20th century. The installation of hydropower, as a percentage of total capacity, waned after World War II, when thermal power became dominant. Small hydropower received renewed emphasis in the 1980s, in the wake of oil crises experienced in the 1970s.

${ }^{2}$ ORNL New Streamreach Development Report, Reclamation and Corps non-powered dams and canal reports, etc.

${ }^{3}$ Information available at http://nhaap.ornl.gov/sites/default/files/ORNL_NSD_FY14_Final_Report.pdf
} 
- identify new technology and ancillary efforts that will lower the cost of new smallhydropower development

- provide research and development interests with an industry assessment of innovation successes and promising developments for use in program planning

- suggest how industry and government can partner to execute research, development, and demonstration that

- identify and accelerate projects that are explicitly innovative

- incentivize and enable first-adopter risk-taking

- disseminate details of state-of-the-art technology, lessons learned, and successful innovations

\section{Assessments of Hydropower Development Opportunities}

\section{DOE New Stream Reach Development Assessment}

The New Stream Reach Development (NSD) assessment considers existing flow hydrography and hydrology, existing dams and plants, topography, and environmental factors to identify the potential for new hydropower capacity. The NSD assessment uses detailed three-dimensional geospatial, hydrologic, and hydraulic modeling to analyze the potential for new hydropower within undeveloped (and un-impounded) stream segments. The NSD assessment addressed only one class of hydropower potential. DOE has also addressed the potential for development at nonpowered dams, upgrading of existing hydropower facilities, development of new pumped storage plants, and energy extraction from small conduit projects. ${ }^{4}$

The estimated technical resource capacity for NSD is $84.7 \mathrm{GW}$, and total undeveloped NSD generation is estimated at 460 TWh per year. A minor portion of this potential is excluded from development by law (national parks, wild and scenic rivers, and wilderness areas), reducing the available NSD potential to $65.5 \mathrm{GW}$, or somewhat less than the current existing US conventional hydropower nameplate capacity (excluding pumped storage). Undeveloped NSD generation with those areas excluded is estimated to be 347.3 TWh per year, or about $128 \%$ of the average 20022011 net annual generation from existing plants. ${ }^{5}$

\section{Bureau of Reclamation}

The Bureau of Reclamation (Reclamation) completed two assessments in 2011 and 2012 of the potential for adding hydropower facilities to Reclamation-controlled water delivery infrastructure:

- Hydropower Resource Assessment at Existing Reclamation Facilities ${ }^{6}$ (March 2011): This report identifies 191 sites with an aggregate 268 MW (1,168 GWh of annual energy production at 50\% capacity factor). Of those 191 sites, 71 were deemed to have sufficient economic benefit to warrant further analysis.

- Site Inventory and Hydropower Energy Assessment of Reclamation Owned Conduits ${ }^{7}$ (March 2012): This report, which supplements the March 2011 report, focuses on Reclamation's conduit and canal infrastructure. It identifies 373 small conduit sites having the potential for more than $103 \mathrm{MW}$ (365 GWh of annual energy production at 40\% capacity factor).

\footnotetext{
${ }^{4}$ http://energy.gov/eere/water/hydropower-resource-assessment-and-characterization

${ }^{5}$ http://nhaap.ornl.gov/sites/default/files/ORNL_NSD_FY14_Final_Report.pdf

${ }^{6} \mathrm{http} / / /$ www.usbr.gov/power/AssessmentReport/index.html

${ }^{7}$ http://www.usbr.gov/power/CanalReport/index.html
} 
The permitting mechanism for non-federal development at Reclamation facilities is the Lease of Power Privilege Process. ${ }^{8}$ However, Lease of Power Privilege does not alter the priority of authorized project purposes at Reclamation facilities, which typically prioritize storage and delivery of water for irrigation

\section{US Army Corps of Engineers}

The US Army Corps of engineers (USACE) performed an investigation, Hydropower Resource Assessment at Non-Powered USACE Sites (July 2013), to evaluate the potential for adding hydroelectric power at its existing non-powered water conveyance projects. ${ }^{9}$ In contrast to the 75 facilities with an aggregate installed capacity of $21,000 \mathrm{MW}$, or about $24 \%$ of total US hydropower capacity, there are 419 USACE owned and operated non-powered dams identified in the report. It identifies 223 of these dams as having greater than $1 \mathrm{MW}$ of hydropower potential, with no obvious factors that would hinder hydropower development and no Federal Energy Regulatory Commission (FERC) hydropower license for non-federal development.

\section{The Importance of Innovating Early in Project Development}

Innovation is important to getting meaningful amounts of untapped US hydropower potential developed. However, it is important that innovations be conceived, developed, and integrated into project design and development at the appropriate time. The most effective innovations are those that can influence the initial project design and development efforts and outcomes. In the case of innovative equipment, specifications and performance must be fully validated and available to project designers at the outset of project development. Alternatively, there must be extra research and development support to address not only the direct costs and risks of the innovative equipment but also the potential indirect cost impacts of the equipment within overall project design and construction. Once project development has progressed significantly beyond exploratory design stages, there is often a narrow focus on completing construction and commissioning the project as quickly as possible with minimum cost. The potential rewards of introducing innovation in the latter stages of a project tend to be small, whereas costs and reliability risks are greater, within the context of overall project development.

\section{Developer Types and Roles}

A variety of organizations engage in hydropower development. These entities, hereafter referred to as “developers," range in size and capability from individuals to large commercial enterprises. Public institutions may be developers, including small municipalities, utility districts, large metropolitan governments, and state agencies. The USACE, Reclamation, and the Tennessee Valley Authority (TVA) functioned as federal public developers in the 20th century-new development by these federal agencies would require Congressional authorization and appropriation of federal funds. Private developers may be as small as one entrepreneur or as large as a regional investor-owned utility or independent power producer. Public and private developers differ in their access to and cost of capital for project development, which can affect the feasibility and timelines of the development that each can undertake.

\footnotetext{
${ }^{8}$ http://www.usbr.gov/power/lopp

${ }^{9}$ http://cdm16021.contentdm.oclc.org/cdm/ref/collection/p266001coll1/id/2333
} 
When suitable conditions are present, a developer may envision an opportunity and then take the necessary steps to bring the opportunity to fruition. The development of hydropower plants is sometimes the principal purpose, or the only purpose, of a developer organization. In other cases, a proximate opportunity may lead an individual or organization to take on the role of developer. For example, a mothballed hydroelectric facility at a dam within a city might inspire individuals within the city government to seek to restore it to electricity production for the benefit of the city, and the city to take on the developer role.

The role of the developer is crucial in directing the iterative process, involving science and art, that leads to success. The developer must engage communities of practice and expertise in the following areas:

- Overall process and project management

- Resource assessment and site selection

- Cost/revenue projection

- Schedule development

- Financial modeling

- Financing

- Licensing and permitting

- Engineering design and procurement

- Power marketing and transmission interconnection

- Construction and commissioning

- Operations and maintenance

The developer must attend to each of these areas with diligence to shepherd a project to successful completion. Above all, cost and revenue projections must be continually updated as the project unfolds and new information is acquired to ensure that a favorable balance of revenue versus costs is maintained.

\section{Barriers to Development}

The authors have identified these barriers to new hydropower development:

- Scattered information-Information useful for developers and consultants is rarely available in a centralized, searchable format. This results in higher costs for initial site assessment.

- Burdensome regulatory and licensing processes-It is common for the licensing of new projects to require several years, even if project impacts are minimal. Multiple jurisdictions are involved in most projects, often requiring duplicative information submittals and review processes.

- Non-standard designs and manufacturing-Standard designs are not commonly available, so each new project typically has a unique and site-specific design. This engenders more design effort, more environmental review effort, and increased manufacturing effort, each of which increases schedule and cost.

- Uncertainty and risk prior to financing and construction-The time required to advance a project from concept to financial prospectus and from financing to the start of construction affects the probability of development success. Reducing the uncertainty and risk that persists 
during these lengthy initial phases of development could increase the attractiveness of hydropower projects as investments.

- Unknown or uncertain revenue projections-Revenue is projected based on future estimates of energy markets that can change drastically in a very short time during a very long development process. The absence of a willing and creditworthy counterparty for a power purchase agreement makes it difficult to project revenue, which discourages investments to develop hydropower projects.

The ideas presented in this report have the potential to help to address these challenges. 


\section{Section 2. Ideas and Solutions}

This section describes ideas that are considered to have potential for enhancing and increasing hydropower development. Inclusion of an idea does not indicate a consensus among contributors regarding the merit of the idea. Each idea is briefly described, along with the current context for the idea and a vision for how the idea would influence hydropower development. Also included are answers to these important questions:

- Who would benefit if this idea were pursued?

- How would it contribute to getting more hydropower projects built?

- What organization(s) could best pursue this idea?

- Who has the requisite knowledge, skills, and so on, to pursue this idea?

- How much would it cost?

- How long would it take to achieve meaningful results?

A short outline of possible next steps to advance each idea is also provided. The ideas are organized into topic-related subsections.

Table 1 lists the ideas that are subsequently discussed in this report. The ideas fall into eight general categories:

- Improved Tools for Siting, Prequalification, and Feasibility Determination

- New and Improved Design Tools_-Guidelines and Standards

- Improved Access to Design-related Information-Online Toolboxes and Databases

- New Hydropower-Specific Education, Training, and Outreach

- Advanced and Improved Technology, Materials, and Manufacturing

- Standardized and Modular Designs

- New and Improved Electrical Standards and Practices

- Tools for Commissioning, Operation, and Maintenance 
Table 1. Ideas for facilitating new hydropower development

\begin{tabular}{|c|c|c|c|c|c|}
\hline Idea & 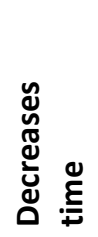 & 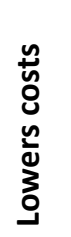 & 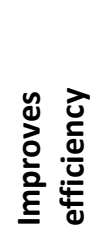 & 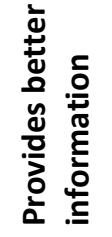 & 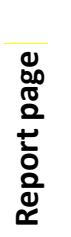 \\
\hline $\begin{array}{l}\text { Improved Tools for Siting, Prequalification, and Feasibility } \\
\text { Determination }\end{array}$ & & & & & 10 \\
\hline $\begin{array}{l}\text { 1. Develop a website/portal enabling access to public information to } \\
\text { help developers accelerate site assessment }\end{array}$ & $\checkmark$ & $\checkmark$ & & $\checkmark$ & 10 \\
\hline $\begin{array}{l}\text { 2. Study a selected region/locale to assess opportunities for siting } \\
\text { new small-hydropower installations }\end{array}$ & $\checkmark$ & & & $\checkmark$ & 13 \\
\hline $\begin{array}{l}\text { 3. Develop improved tools for early project configuration and cost } \\
\text { estimating }\end{array}$ & $\checkmark$ & $\checkmark$ & & $\checkmark$ & 14 \\
\hline $\begin{array}{l}\text { 4. Enhance the DSIRE online database to include and highlight } \\
\text { hydropower-related information }\end{array}$ & & & & $\checkmark$ & 16 \\
\hline New and Improved Design Tools_-Guidelines and Standards & & & & & 17 \\
\hline 5. Develop a guide for draft tube configuration & $\checkmark$ & $\checkmark$ & & $\checkmark$ & 17 \\
\hline $\begin{array}{l}\text { 6. Develop design standards and models for siphon hydroelectric } \\
\text { plants to support rapid development }\end{array}$ & & & & $\checkmark$ & 18 \\
\hline $\begin{array}{l}\text { 7. Develop design standards and best practices for the application of } \\
\text { new penstock materials }\end{array}$ & & & & $\checkmark$ & 20 \\
\hline $\begin{array}{l}\text { 8. Develop a guideline for capital cost-saving "fit for purpose" } \\
\text { project designs }\end{array}$ & $\checkmark$ & $\checkmark$ & & & 21 \\
\hline $\begin{array}{l}\text { Improved Access to Design-related Information-Online Toolboxes } \\
\text { and Databases }\end{array}$ & & & & & 22 \\
\hline 9. Develop an online hydropower construction materials toolbox & & $\checkmark$ & & $\checkmark$ & 22 \\
\hline $\begin{array}{l}\text { 10. Develop an online repository of information for gates and } \\
\text { operators }\end{array}$ & $\checkmark$ & & & $\checkmark$ & 24 \\
\hline $\begin{array}{l}\text { 11. Develop an online inventory of fish screens, bypass systems, lifts, } \\
\text { and ladders }\end{array}$ & $\checkmark$ & & & $\checkmark$ & 25 \\
\hline $\begin{array}{l}\text { 12. Develop a procurement toolbox for hydropower equipment, } \\
\text { components, and systems }\end{array}$ & $\checkmark$ & $\checkmark$ & & & 26 \\
\hline New Hydropower-Specific Education, Training, and Outreach & & & & & 28 \\
\hline $\begin{array}{l}\text { 13. Prepare and distribute white papers on new small-hydropower } \\
\text { technology }\end{array}$ & & & & $\checkmark$ & 28 \\
\hline $\begin{array}{l}\text { 14. Develop a hydropower-specific core education curriculum for } \\
\text { hydropower engineers }\end{array}$ & & & $\checkmark$ & $\checkmark$ & 29 \\
\hline 15. Develop a training course for small-hydropower operators & & $\checkmark$ & & $\checkmark$ & 30 \\
\hline Advanced and Improved Technology, Materials, and Manufacturing & & & & & 31 \\
\hline $\begin{array}{l}\text { 16. Expand the use of alternative and composite materials in } \\
\text { hydropower plant components }\end{array}$ & $\checkmark$ & $\checkmark$ & $\checkmark$ & $\sqrt{ }$ & 31 \\
\hline $\begin{array}{l}\text { 17. Develop strategies for smaller and reduced reinforced-concrete } \\
\text { structures }\end{array}$ & $\checkmark$ & & $\checkmark$ & $\checkmark$ & 33 \\
\hline $\begin{array}{l}\text { 18. Develop new turbine technology to reduce or eliminate civil } \\
\text { construction }\end{array}$ & & $\checkmark$ & & $\checkmark$ & 35 \\
\hline
\end{tabular}




\begin{tabular}{|c|c|c|c|c|c|}
\hline 19. Accelerate three-dimensional printing of turbines and equipment & $\checkmark$ & $\checkmark$ & $\checkmark$ & $\checkmark$ & 36 \\
\hline $\begin{array}{l}\text { 20. Establish specifications, criteria, and validation methods for fish- } \\
\text { friendly turbines }\end{array}$ & & $\checkmark$ & & $\checkmark$ & 37 \\
\hline 21. Stimulate technology innovation relevant to new hydropower & & & & $\checkmark$ & 40 \\
\hline Standardized Modular Designs & & & & & 42 \\
\hline 22. Develop standard designs for conduit hydropower & $\checkmark$ & $\checkmark$ & $\checkmark$ & $\checkmark$ & 42 \\
\hline $\begin{array}{l}\text { 23. Develop standardized, factory-assembled small-hydropower } \\
\text { equipment packages with ancillary equipment mounted on skids } \\
\text { to speed construction }\end{array}$ & $\checkmark$ & $\checkmark$ & $\checkmark$ & $\checkmark$ & 43 \\
\hline $\begin{array}{l}\text { 24. Simplify project operations and maintenance by using modular } \\
\text { components }\end{array}$ & $\checkmark$ & $\checkmark$ & $\checkmark$ & $\checkmark$ & 44 \\
\hline $\begin{array}{l}\text { 25. Develop a library of three-dimensional equipment drawings and } \\
\text { configurations }\end{array}$ & $\checkmark$ & $\checkmark$ & & $\checkmark$ & 45 \\
\hline New and Improved Electrical Standards and Practices & & & & & 46 \\
\hline $\begin{array}{l}\text { 26. Develop standard electrical and control configurations for new } \\
\text { hydropower plants }\end{array}$ & $\checkmark$ & $\checkmark$ & $\checkmark$ & $\checkmark$ & 46 \\
\hline 27. Develop standard substation configurations & $\checkmark$ & $\checkmark$ & $\checkmark$ & $\checkmark$ & 47 \\
\hline $\begin{array}{l}\text { 28. Develop small-hydropower standards for the updated National } \\
\text { Electrical Code }\end{array}$ & $\checkmark$ & $\checkmark$ & $\checkmark$ & $\checkmark$ & 48 \\
\hline $\begin{array}{l}\text { 29. Develop and promote standard interconnection methods and } \\
\text { standards for small-hydropower and micro-hydropower } \\
\text { installations }\end{array}$ & $\checkmark$ & $\checkmark$ & $\checkmark$ & $\checkmark$ & 49 \\
\hline $\begin{array}{l}\text { 30. Explore expanded use of net metering in small-hydropower and } \\
\text { micro-hydropower installations }\end{array}$ & & $\checkmark$ & & $\sqrt{ }$ & 50 \\
\hline Tools for Commissioning, Operation, and Maintenance & & & & & 51 \\
\hline $\begin{array}{l}\text { 31. Develop best-practices guidance for small-hydropower project } \\
\text { commissioning and operation and maintenance plans }\end{array}$ & $\checkmark$ & $\checkmark$ & & & 51 \\
\hline
\end{tabular}




\section{Improved Tools for Siting, Pre-qualification, and Feasibility Determination}

\section{Idea 1: Develop a website/portal enabling access to public information to help developers accelerate site assessment}

The availability of more extensive centralized, searchable web-based information useful for site evaluation could facilitate early assessments. The earlier in the project cycle that developers and agencies can understand site-related issues (and how they can be mitigated), the better. Online availability of commonly used baseline information could

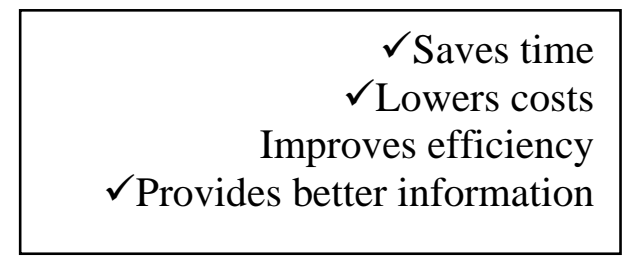
facilitate integrated assessment by developer, regulatory, and resource agency personnel. This could enable parties to work together to identify assessment issues, needed studies, and likely mitigation needs.

A website could be designed with common sources of information, best practices, successful mitigation strategies, and generally acceptable activities. It could help enhance best practices, streamline assessments, and reduce up-front project costs.

\section{Current Context}

Once a site is being considered for development, available site- and area-specific information is reviewed to aid understanding of the site and to identify issues that could render a project infeasible. Much information is publicly available that is relevant to many prospective development sites. Data from federal agencies can be of paramount importance, such as that from FERC, the U.S. Geological Survey (USGS), the National Oceanic and Atmospheric Administration, land and resource agencies, DOE, and others. State and local organizations also have information resources and studies that may be relevant. There is a general concern among the authors that redundant efforts occur because such information is not centralized and readily available. The lack of easily accessible information may also hinder the identification of critical issues early in the development process.

Assessments often begin by accessing the knowledge bases of particular consultants or agencies. Local public entities and public interest groups may also be keepers of information helpful in making project assessments. Often, information resides in local college libraries, masters or doctoral theses, or other academic documents. A literature review may be time consuming and yet not result in the discovery of key information and background data for an assessment. Although the Internet has improved access to information, it does not provide validation of information. Moreover, much information that previously has been public - and free-has been captured and is made available online only upon payment of a fee. 
Federal data in particular, with improved accessibility and usability, has great potential to help the hydropower industry increase development (see the sidebar). Hydropower resource assessments have recently been published by ORNL, Reclamation, and USACE. Yet in some cases, because of different data and assumptions, there are different outcomes for the same site. From the users' perspective, the data are more important than which agency is compiling it, and the results would be more valuable if they were combined or referenced in a central location. This process could also lead to buy-in from the various agencies and stakeholders that contribute information.

Examples of information that that could improve the development process through web portal availability include

- Federal data, such as information on threatened and endangered species

- FERC (or Reclamation) licensing history

- USGS gauge data

- Electricity pricing data

- Credible third-party information, such as the Electric Power Research Institute's recently completed nationwide hydrokinetic resource assessments

- Information gathered by state agencies such as the California Energy Commission statewide conduit resource assessment or the Colorado Department of Agriculture statewide agricultural hydropower resource assessment

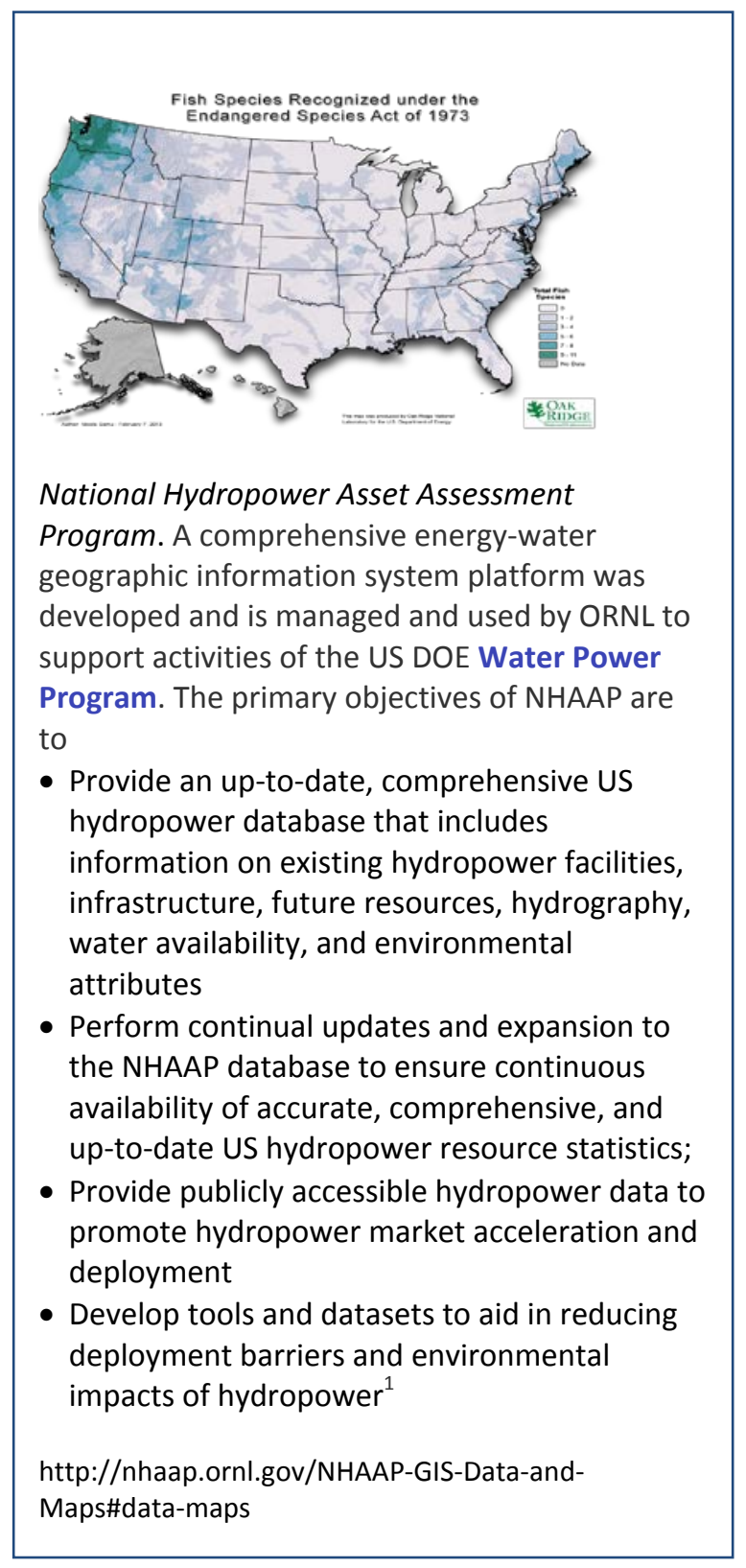

- Area or site-specific studies conducted by public utilities or water districts, such as the assessment of hydrokinetic potential in the mid-Columbia region by the Chelan County Public Utility District

\section{Vision}

A public web-based tool and library enables professionals involved with site assessment and permitting to gain access to accurate site-related information and prior relevant assessment work. The assessment team can easily access key information, including likely mitigation needs and strategies. This portal is in the public domain and allows searches by topic and geography (i.e., location). Geographic information system (GIS) -based data is available from federal agencies (subject to security guidelines and protocols). 
The web portal provides access to a wide variety of relevant information. For example, irrigation districts with interests in prospective power project development post available data on their conduits and canals. This information is thus available to interested parties and enables them to assess the potential of and propose beneficial development.

The availability of this capability provides more comprehensive information for preliminary site assessment. It also helps identify likely mitigation needs at a site with less investment of time and effort than previously required. The need for expensive, time-consuming literature searches is avoided.

\section{Next Steps}

1. Review typical preliminary site assessments for various geographical regions; determine the data sources and materials used.

2. Engage qualified professionals to screen the data and information to identify key topics (and keywords).

3. Develop a prototype web-based library that centralizes key data, documents, and information, including other site-related assessments and environmental impact statements, technical and scientific papers, and seminar presentations.

4. Establish a time frame for delivering a working prototype of this web-based tool.

5. Engage agencies having related interests to collaborate in the development. 


\section{Idea 2 : Study a selected region/locale to assess opportunities for siting new small- hydropower installations}

Many of the opportunities for achieving improvements in small hydropower could come from economies of scale.

That is, increasing the market for a particular component, package, or even an entire hydropower installation to a hundred or a thousand rather than a few units could enable supply at lower costs.

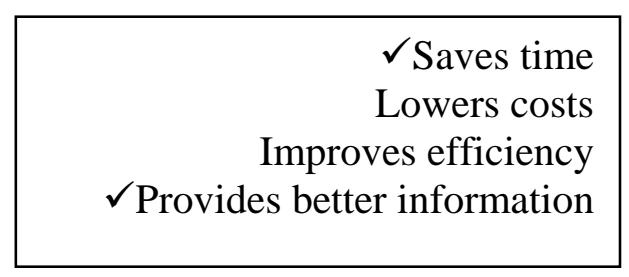

\section{Current Context}

At present, it can be difficult for many prospective developers of small hydropower to do the investigative work necessary to identify similar, prospectively developable sites in a local area or region. Yet, it is the economies of scale that might be achieved through development of multiple, similar sites in a region that might tip the balance to make such developments feasible.

\section{Vision}

Study and assessment of a selected region have identified hundreds of sites that have potential for small-hydropower development. Depending on prevailing electricity costs (and available applicable renewable energy incentives) that drive project economics, these sites have been ranked into feasibility categories. From among the nearer-term feasibility categories, sites have been assessed to determine classes of projects that are somewhat similar to warrant multiple site projects sufficient to achieve economies of scale. These economies of scale apply across the entire range of development activities, including the purchase of hydroelectric equipment.

\section{Next Steps}

1. Based on prior high-level resource assessments, select a region or locale for more detailed examination to identify prospective individual small-hydropower development sites. The number of prospective sites in the selected area should range from one to perhaps several thousand.

2. Conduct sufficient research to further qualify, characterize, and rank sites for development. Establish multiple tiers of sites based on potential: e.g., Tier A (developable present-5 years); Tier B (developable 5-10 years); etc.

3. Based on the outcome of this assessment, select other regions/locales for similar examination. 


\section{Idea 3: Develop improved tools for early project configuration and cost estimating}

There is a need for an improved low-cost, publicly available software tool for developing early project configuration and cost estimates. Automated, intelligent tools can reduce engineering man-hours during early project assessment and provide early, yet reliable, project cost estimates and schedules.

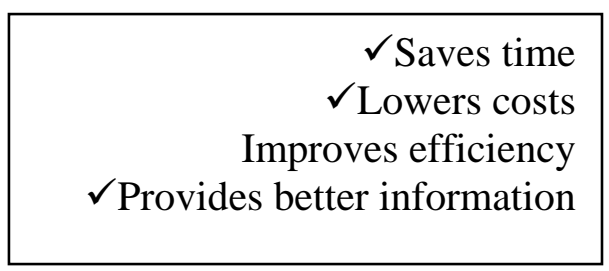

Such a tool would allow federal, state, and local agencies to create a common list of concerns and standard modules to address project-specific concerns early in the project cycle. As a project comes to licensing and permitting, a standardized format would facilitate evaluation. The agencies could access the tools to perform "what if" analyses.

The tool would serve owners' interests in reducing the number of studies and steps required during the early phases of project development. It would also be designed to provide early identification of mitigation requirements and costs and prospective fatal flaws.

Early estimation of costs and schedule requirements would be a key goal, along with identification and reduction of risks and uncertainties.

\section{Current Context}

Various organizations have developed relevant calculation methodologies, computer programs, technical specifications, and work standards. ${ }^{10}$ Academic institutions and professionals have developed calculation techniques and work methods that make use of computer-generated calculations and drawings. Enterprise-wide intranets, personal computers, and advanced computer programs have allowed the recent development of calculation tools that have revolutionized the engineering industry and its approach to project conceptualization and design.

Calculations are normally accomplished using spreadsheets and engineering software, allowing engineers to perform calculations and then replicate them for the next similar project task. ${ }^{11}$ Current software facilitates reliable calculations and provides clear documentation of criteria and assumptions. Some software programs are directed to specialized aspects of engineering problems - e.g., finite element analysis, finite difference analysis, specialized hydrologic and hydraulic programs, static and dynamic analysis programs. This leads to increasing standardization and familiarity, which further facilitates review and quality verification activities.

\footnotetext{
${ }^{10}$ For example, DOE, National Hydropower Association, USACE, Reclamation, TVA, ASCE, ASME, IEEE, ASTM, AWWA, ACI, AISC

${ }^{11}$ Microsoft Excel ${ }^{\circledR}$ spreadsheets and Access ${ }^{\circledR}$ databases are used for large data-set calculation; both rely on open architecture, and allow for the incorporation of macros and engineering formulas. Mathcad is an industry-standard software for solving, documenting, sharing, and reusing vital engineering calculations. These tools are illustrative of a wide range of computational software that is currently available.
} 
A recent development in engineering tools is the linking of multiple engineering discipline calculations to define project features, from the point of hydraulic diversion through all project features to the point of downstream discharge. This linkage shortens development schedules and reduces costs for hydroelectric projects. The objective is to define the hydrologic, hydraulic, civil, structural, mechanical, electrical, and control calculations to obtain an overall project concept based on sound engineering design principles. Such linked computation leads to an improved level of confidence in terms of defining the project features, equipment selection, and anticipated associated costs.

This type of software can provide initial sizes of structures and flow lines, as well as powerhouse equipment specifications. It also can generate preliminary material quantities and cost estimates. Examples include RETScreen ${ }^{\circledR}$ and HydroHelp (Fig. 1). ${ }^{12}$

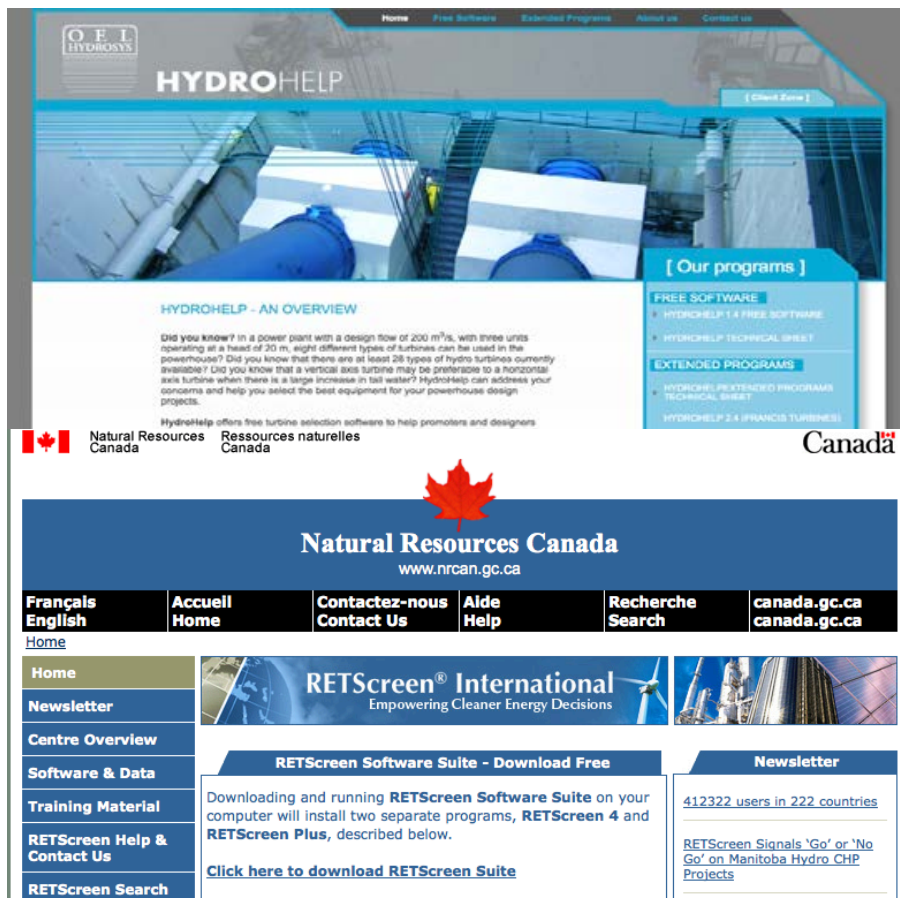

Fig. 1. Screens for RETScreen (top) and HydroHelp.

\section{Vision}

A publicly available inexpensive tool for defining project parameters and estimating costs enables qualified users to develop a preliminary project concept within a few hours. The developed initial cost estimate has higher reliability than previously available and permits a firstorder assessment of project financial viability. Limitations of previous spreadsheet-based software have been resolved, and users can customize the project elements.

Various calculations that previously required the use of multiple tools are performed within a single tool, which allows an experienced user to conceptually define a project in a few hours. The tool enables "what if” computations related to environmental effects, project costs, and schedule. The tool produces estimates of schedule and cost risks and is applicable across multiple project phases. It makes use of GIS-configured data , e.g., hydrologic, topographic, geologic, land use, and environmental data.

\section{Next Steps}

1. Catalog and assess existing tools.

2. Determine key attributes needed for new, more comprehensive tool.

3. Prepare plan and schedule for developing new tool.

\footnotetext{
${ }^{12}$ Information on RETScreen ${ }^{\circledR}$, developed under the auspices of Natural Resources Canada, is available at http://www.retscreen.net/ang/home.php. Information on HydroHelp is available at http://www.hydrohelp.ca/eng/home.htm.
} 


\section{Idea 4: Enhance the DSIRE online database to include and highlight hydropower- related information}

The Database of State Incentives for Renewables \& Efficiency (DSIRE) is a powerful and useful tool that should be updated and kept current specifically for hydropower. ${ }^{13}$ The DSIRE website is an effective tool that provides information on programs and incentives for renewable energy. These are currently divided between "solar" and "renewables and efficiency"; however, the website promises changes during 2014. Adding a hydropower element could be very beneficial to hydropower development interests.

\section{Current Context}

DSIRE is a relatively comprehensive source of information on US incentives and policies that support renewables and energy efficiency. With regard to hydropower, though, the DSIRE information is often out of date and inaccurate. Moreover, at state and local levels, the policies, incentives, and available funding are continually changing.

\section{Vision}

DSIRE provides an improved hydropower searchable online tool that includes accurate and regularly updated information about specific policies and incentives prospectively beneficial to hydropower. Where applicable, the website also describes tax-related incentives, including accelerated depreciation and tax credit programs. Further, the website includes information on loan and grant programs (and qualification criteria). State-by-state information on public utility/regulatory commissions is provided, as is information regarding specific legislation and directives pertaining to each state's renewable energy strategy (e.g., where a state has a broad goal such as $50 \%$ renewables by 2050.) Information is included on whether states include net metering, open access requirements for adding renewables, and so on.

\section{Next Steps}

1. Ensure that DSIRE includes hydropower as a focus so that hydropower-related information is easily accessed. ${ }^{14}$

2. To incorporate continual changes in policies, incentive programs, and available funding, ensure that DSIRE is regularly updated so that it maintains high-quality information.

\footnotetext{
${ }^{13}$ From the DSIRE website home page (http://www.dsireusa.org/): "DSIRE is the most comprehensive source of information on incentives and policies that support renewables and energy efficiency in the United States. Established in 1995, DSIRE is currently operated by the N.C. Solar Center at N.C. State University, with support from the Interstate Renewable Energy Council, Inc. DSIRE is funded by the U.S. Department of Energy.” As of June 23, 2014, the website reports: “... a new, modernized DSIRE is under construction. ... The new DSIRE site will be available in the summer of 2014." ${ }^{14}$ Prospective relevant information for inclusion in DSIRE includes information compiled by the National Hydropower Association on hydropower-related incentive programs. In addition, the Clean Energy States Alliance has published Environmental Rules for Hydropower in State Renewable Portfolio Standards (2013). The Lawrence Berkeley National Laboratory-Electricity Markets and Policy Group has published A Survey of State-Level Cost and Benefit Estimates of Renewable Portfolio Standards (2014).
} 


\section{New and Improved Design Tools-Guidelines and Standards}

\section{Idea 5: Develop a guide for draft tube configuration}

A guide for draft tube configuration would help hydropower plant designers and developers by aiding them in determining the optimal tradeoff between construction costs and efficiency gains and losses.

\section{Current Context}

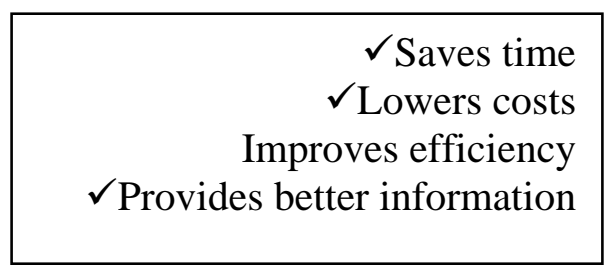

The current practice is to optimize the efficiency of hydropower plant draft tubes by a combination of lowering the turbine centerline and establishing a long, wide draft tube configuration. Older units often employed shorter, narrower draft tubes, or Moody Spreading draft tubes, which did not require the depth and width of excavation required by commonly used modern designs. Yet, sacrificing some efficiency in the draft tube, might reduce civil costs to provide a more optimal, i.e., economical, configuration.

\section{Vision}

A guide aids developers and engineers in configuring turbine equipment and draft tubes in ways that reduce to an optimal degree the civil costs associated with excavation, concrete, and other building materials. By reducing the depth of excavation required (compared with prior practice), temporary construction works are reduced because the depth of excavation and the powerhouse width have been reduced to some degree. Investigations conducted in the process of developing this guideline has determined the degree to which maximum draft tube efficiency increases the civil costs of a project and the degree to which losses in draft tube efficiency are offset by savings in the construction costs of the powerhouse, draft tube, and tailrace.

\section{Next Steps}

1. Assemble technical publications on draft tube design, technical guides, and draft tube configurations.

3. Prepare a state-of-the-art review of draft tube design methods.

4. Consult and hold a workshop with hydropower turbine manufacturers and plant designers. Address draft tube configuration options that would reduce excavation costs. Consider shape and other factors that would reduce powerhouse and civil costs, toward establishing acceptable tradeoffs between draft tube efficiency and total plant costs. Prepare a draft guideline on draft tubes; conduct peer review.

5. Publish the guide. 


\section{Idea 6: Develop design standards and models for siphon hydroelectric plants to support rapid deployment}

Siphon hydroelectric units are infrequently used and not well known, but they have long been used for smaller hydroelectric installations. This type of plant can be especially attractive for adding hydropower at an existing non-powered dam. It has often proved to be a cost-effective,

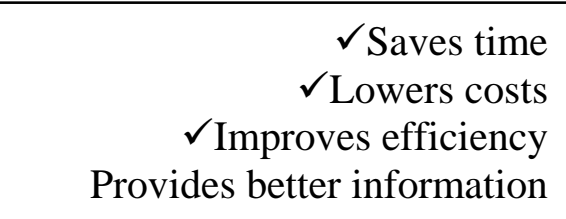
timesaving option because a siphon plant moves the water over, not through, the dam. This avoids the often time-consuming and expensive work of developing a water passage. Moreover, cofferdams are not needed and the uncertainty and risks of excavating into an existing dam are avoided. Yet because they remain relatively uncommon, the use of siphon units could be facilitated by the availability of a trustworthy application guideline.

\section{Current Context}

Several manufacturers have introduced siphon turbine-generators to the US market (Fig. 2). ${ }^{15}$ These units could be attractive to owners of non-powered dams because they do not like to modify existing dams, especially in light of possible dam safety implications. Traditionally, where siphons are used, the siphon typically is constructed of steel and reinforced concrete.

\section{Vision}

Siphons are widely used to generate power at non-power dams because they can be installed without substantial modification of existing dams. Owing to their advantages, larger multiple siphon installations are becoming commonplace. The use of advanced materials

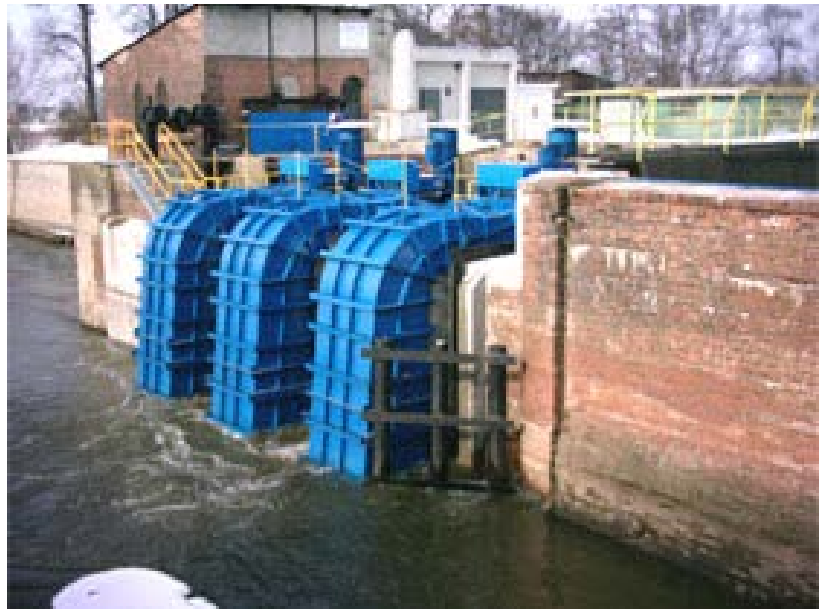

Fig. 2. This siphon turbine was installed on an existing weir in southern Poland in 2006. The same company is constructing the Head of the $U$ hydropower project in Idaho using this technology. for constructing siphons makes them light and easy to install.

\footnotetext{
${ }^{15}$ http://www.mavel.cz/install-mainframe.html
} 


\section{Next Steps}

1. Conduct a literature search to assemble information on the design of siphon units and on existing installations. Seek physical model study reports if available. ${ }^{16}$

2. Prepare report on owner/operator experiences with this type of equipment, including recommendations for improvements. (For example, is there scope for improvement of siphon priming systems?)

3. Consider the prospects for using advanced materials for siphon construction.

4. Develop and publish a best-practices siphon design and construction guideline.

\footnotetext{
${ }^{16}$ The following DOE-sponsored reports are available from the US Department of Commerce-National Technical Information Service: Report on Siphon Penstocks for Hydroelectric Projects: Small-Scale Hydroelectric Power (1989), Accession No. DE90000985; Siphon Penstock Installations at Hydroelectric Projects: A Survey of Design, Construction and Operating Experience (1989), Accession No. DE90001749; Report on Siphon Penstocks for Hydroelectric Projects (1989), Accession No. DE90008613
} 


\section{Idea 7: Develop design standards and best practices for the application of new penstock materials}

Non-steel and cast iron materials are often lower in cost than traditionally used steel for penstocks and should be considered as a cost-saving measure. These materials can often be installed and joined more quickly and with less civil construction cost.

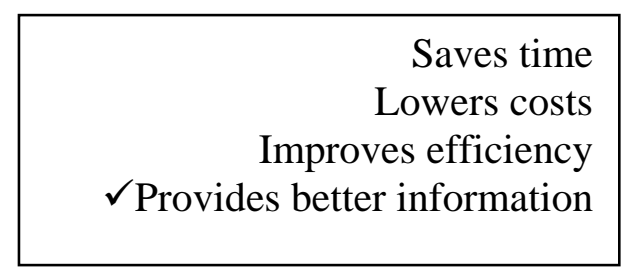

The American Society of Civil Engineers (ASCE) and the petroleum and steel pipe industry, among others, have developed standard publications applicable to the use of steel penstocks. Newer materials are not adequately addressed by industry consensus standards and design guidance. These materials include fiberglass-reinforced plastic, centrifugally cast fiberglassreinforced polymer mortar (e.g., Hobas ${ }^{\circledR}$ ), and high-density polyethylene (e.g., Whelolite ${ }^{\circledR}$ ). These pipeline materials, which could lower cost and shorten schedules, often are not considered owing to the lack of information on design and industry-accepted best practices. Design standards could increase the beneficial use of these materials.

\section{Current Context}

There are new pipeline and penstock materials for which product-specific limited information related to application, design, and installation is available. Although some relevant information is available from the manufacturers, the lack of industry design standards and best practices for these materials limits their use.

\section{Vision}

Design standards, publications, and best practices are available addressing the use of new pipeline and penstock materials. These materials are routinely used to lower costs.

\section{Next Steps}

1. Perform a literature search on non-steel penstock/pipeline materials, including obtaining information from manufacturers. Seek articles, technical publications, project profiles, lessons learned, and best practices.

2. Encourage and support the establishment of a committee or working group within the ASCE and/or the American Society of Mechanical Engineers to develop industry standards for the use of non-steel and cast iron pipeline and penstock materials.

3. Develop an engineering guideline for the use of these penstock/pipeline materials. 


\section{Idea 8: Develop a guideline for capital cost-saving "fit for purpose" project designs}

Because they tend to follow long-established principles, hydropower project designers, owners, and developers generally seek to prepare optimized project designs that enable maximum energy production. However, in many cases, a simpler, cheaper design solution might provide the owner with better value and adequate results at a far lower

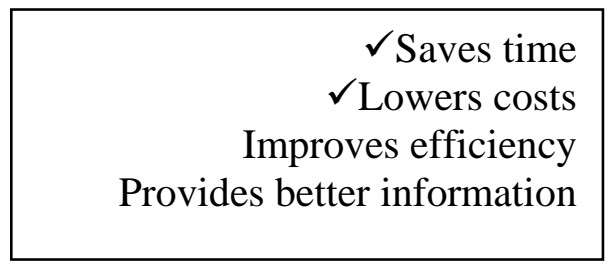
investment cost. It could be helpful to have a guideline to help achieve "fit for purpose” results.

\section{Current Context}

There is no industry-accepted guidance or methodology that encourages fit-for-purpose engineering, i.e., that involves a reduced yet adequate level of engineering. Many owners and developers might prefer a fit-for-purpose vs. fully optimized design. They might prefer simpler designs that meet their basic needs. The idea of a less-than-optimized design is counter to current hydropower engineering training. However, one analogy of fit-for-purpose design is in mechanical engineering, where designs sometimes use criteria for a target life span of a specified number of operating hours.

\section{Vision}

A fit-for-purpose design guideline enables hydropower project designers, owners, and developers to achieve adequate project results at a much lower investment cost than prior practices allowed. Simpler designs that meet basic power production needs safely and effectively are easily and quickly constructed. Design costs are reduced. Value engineering methodology is applied throughout the project development cycle.

\section{Next Steps}

1. Prepare a concept paper (white paper) including prospective illustrative examples of fit-forpurpose designs, showing how this approach could be beneficial.

2. Solicit review and comment from experienced hydropower industry practitioners.

3. Present the paper to industry in an open forum or workshop to gain additional feedback.

4. Based on comments and feedback, proceed to develop the fit-for-purpose design guideline. 


\section{Improved Access to Design-related Information-Online Toolboxes and Databases}

\section{Idea 9 : Develop an online hydropower construction materials toolbox}

A searchable online information resource that makes available information pertaining to hydropower plant construction could be useful to hydropower plant designers, developers, and constructors. The architecture would allow open entry of construction-related product data and methodologies. The objective is to make the latest and most up-to-date information available. The toolbox could list information related to construction issues, best practices, trends, and new methods and materials. An accompanying blog could be a useful complement for post issues and inquiries.

\section{Current Context}

There is no online information on hydropower construction. Further, there is little information about material advancements for improving construction results and reducing costs and schedules. Information is scattered among a wide variety of organizations.

\section{Vision}

A comprehensive online collection of hydropower construction-related information is available as an open, public resource. The resource includes a blog feature for posting issues and inquiries. The resource has a topic index and is searchable. Topics catalogued include the following:

- Aggregate and cement types

- Case studies and lessons learned

- Concrete additives

- Concrete design mixes

- Construction methods and best practices

- Contact information from and/or links to various industry organizations

- Cranes, heavy equipment, tools and other construction-related products and equipment

- Dewatering methods

- Excavation and excavation methods

- Geotextiles and geomembranes

- Ground and rock support

- Grout and grouting

- Hot- and cold-weather concreting

- Lists of and/or links to service providers, product, material, fabrication and manufacturing companies working in the hydroelectric sector

- Precast concrete

- Reinforcement and accessories

- Roller compacted concrete

- Shoring and form work

- Structural steel 
- Technical reports, construction-related technical papers

- Value engineering case studies

\section{Next Steps}

1. Conduct a search to identify existing relevant online resources.

2. Build upon existing web-based information and organization websites.

3. Use industry outreach (e.g., conferences, workshops) to frame the architecture of the toolbox.

4. Develop toolbox organization based on workshop input and industry outreach.

5. Build a flexible toolbox that allows service providers, contractors, construction managers, planners, product suppliers, material suppliers, fabricators, and manufacturing companies to add information.

6. Incorporate a blog feature to enable interaction on various construction-related topics.

7. Deploy online toolbox; provide for an editor/manager to screen content additions.

8. Maintain and update the toolbox with current information. 


\section{Idea 10: Develop an online repository of information for gates and operators}

Gates and gate operators (hoisting equipment) are widely used in the hydropower industry, yet it is difficult to obtain up-to-date, timely information on the topic. An online repository for this information would be especially helpful to project owners and operators because it would provide immediate access to both historical and current manufacturers' information and specifications.

\section{Current Context}

Gates and operators are common to most hydroelectric projects and are essential for reliable, safe operation. They typically are subject to frequent operation for a variety of project purposes, ranging from providing environmental flow releases to reservoir regulation and flood control. There is an increasing need for information on gates and operators. Historical data and product information for hydraulic gates are becoming difficult or impossible to locate as printed media become obsolete and as manufacturing and supply organizations change. When such information can be found, it is often in many different locations, as there is no centralized source of engineering and manufacturer information. Moreover, there is no central source of information about advancements in gates and operators, such as compressed air gates and rubber dams, and standardized designs for gates appear to be almost nonexistent.

The problem also appears to be a common issue for much of the specialized equipment used at hydroelectric facilities. Consideration should be given to combining information about gates and gate operators, and about other specialized equipment, in a single online library.

\section{Vision}

An online centralized library of gate and gate operator information is publicly available. This library contains engineering and manufacturer information, case studies, lessons learned, and other information specific to gates and operators.

\section{Next Steps}

1. Conduct a workshop of appropriate industry personnel, including manufacturers, to define information to be maintained and made available in the online repository.

2. Determine who will be responsible for collecting and cataloging the information and managing the repository.

3. Develop a suitable website and provide access to relevant information.

4. Maintain and update the repository. 


\section{Idea 11: Develop an online inventory of fish screens, bypass systems, lifts, and ladders}

Facilitating fish passage and preventing fish mortality are often requirements for new hydropower projects. It would be helpful to have available online information about standard fish screens (fixed and moving), fish bypass systems, lifts, and ladder configurations that are generally accepted by permitting agencies (Fig. 3).

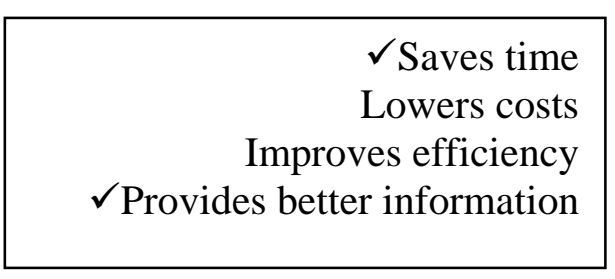

\section{Current Context}

There is currently no inventory of fish mitigation structures. Such an inventory would be helpful to all stakeholders when bypass or upstream migration measures are being discussed, proposed, or designed for implementation. Although articles and papers are available for specific installations, there is no common clearinghouse-no single source that contains an inventory of installations, cost information, expected passage estimates, best practices, lessons learned, and similar information.

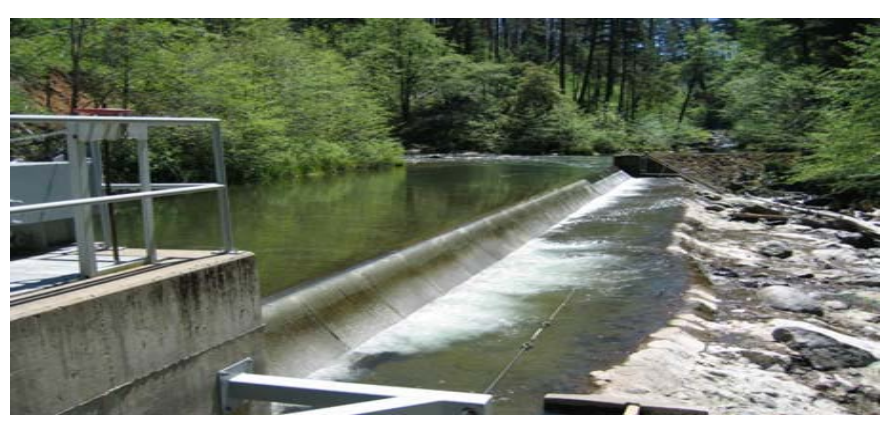

Fig. 3. The Montgomery Creek intake in California is an example of a Coanda screen, a curved or planar inclined screen with tilted wires designed to shear off bottom flow. The geometry allows efficient diversion of clean water with fine mesh filtration so that fish and debris pass over while clean water falls through.

\section{Vision}

An online inventory of fish screens, standard fish bypass systems, lifts, and ladder configurations aids in the conceptual advancement of projects and allows responsible professionals to propose or determine early in the project development cycle appropriate fish mitigation measures. Information available enables cost estimation and estimation of the effects of mitigation measures on hydroelectric operations. Concerned public interest groups and agencies are better assured that fish passage or screening of the appropriate configuration is part of the development plan. The library increases awareness of the existing solutions that have been successfully implemented. Developer risk has been reduced. The information compiled helps guide additional efforts for advancing technologies and methods of fish screening and managing fish passage.

\section{Next Steps}

1. Conduct a comprehensive literature search to assemble published information and identify gaps in information about fish screens, bypass systems, lifts, and ladders.

2. Solicit input from knowledgeable professionals (e.g., at conferences or workshops) regarding information to be included and research needed to close gaps and help establish organizing principles.

3. Determine who will be responsible for managing the repository.

4. Develop a suitable searchable website and populate it with relevant information.

5. Maintain and update the repository. 


\section{Idea 12: Develop a procurement toolbox for hydropower equipment, components, and systems}

The procurement process is typically a complicated, complex process, expensive and time consuming. An interactive procurement database tool could be useful to owners and developers both as a place to start the process and as a way to reduce the complexity of procurement and cut the time between an initial inquiry and final purchase decisions. A procurement tool could promote a more common, standardized approach for both buyers and sellers, reducing both expense and time.

\section{Current Context}

Owners are frustrated with the expense of preparing custom bid documents and the time required to advertise and solicit bids, evaluate them, and decide and then issue purchase orders or negotiate contracts. Equipment manufacturers, fabricators, and suppliers are frustrated with the costs of bidding, one-sided terms and conditions, the follow-on support required throughout the bidding processes, and the less than certain probability of success on any bid. Presently, there are lists of potential suppliers of hydroelectric equipment, and the owners must identify preferred suppliers through an extensive process (technically and financially). The overall process is typically a major effort and can be quite expensive. The box as right highlights standard contracts developed by European consulting engineers.

\section{Vision}

An interactive online procurement database is available that has options for commercial conditions

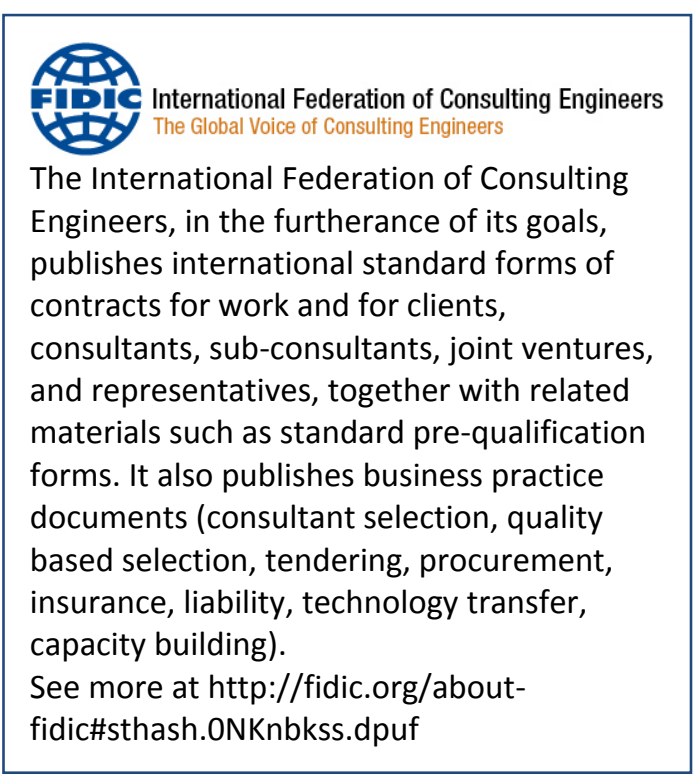
and variations in technical specifications (including the ability to customize if needed) for hydroelectric equipment procurement. The tool contains up-to-date listings of equipment, system, and component suppliers and manufacturers, erection and fabrication companies, and spare parts suppliers. Companies are able to add and update their own information. This online clearinghouse helps match buyers and sellers.

\section{Next Steps}

1. Conduct workshops with industry members to discuss and agree on the scope and direction of a procurement tool. This is a revolutionary idea that will need significant discussion among original equipment manufacturers, legal and technical consultants, and owners. Procurement has traditionally been a process closely controlled by the owner's procurement or legal department and engineers. Close cooperation is necessary to determine what features would be helpful in an online procurement tool (for example, the federal government has specific requirements for all aspects of procurement). 
2. Conduct an analysis of the procurement processes from both technical and commercial perspectives. Identify available standard approaches and how these can be offered within an interactive web-based tool. Allow for customizing of commercial and technical aspects to suit specific requirements.

3. Conduct an analysis of traditional institutional and other barriers (e.g., copyright) to establish mechanisms for cooperation.

4. Develop a database of standard commercial terms and conditions, standard technical specifications, and other helpful guidance, including examples of successful procurements.

5. Gather information from manufacturers, fabricators and suppliers-or have them enter their information - regarding their hydroelectric equipment, systems, and components to develop a comprehensive searchable library. This library would include the standard specifications and options available from manufacturers, fabricators, and suppliers and provide suitable links to manufacturer, fabricator, or supplier websites. This library could be the initial starting point to establish a short list of potential manufacturers, fabricators, and suppliers for a particular procurement. It could also serve as a notification point for a bid qualification or request for proposal, although it would not (for example) be intended to duplicate "Federal Bid Ops."

6. Because of the nature of hydroelectric procurements, there has to be the capability within the procurement tool to seek or add custom information to suit the specific requirements of the procurement. This is often an interactive process, but inquiries could be automated. 


\section{New Hydro-Specific Education, Training, and Outreach}

\section{Idea 13: Prepare and distribute white papers on new small-hydropower technology}

Innovative hydropower technologies are continually being developed. Examples include submersible units, low-head turbines, intakes, new materials applications, and water-towire kits. Considering the relatively rapid changes that are occurring, many people_-including engineers, financiers, and the public at large - could benefit from clear documentation and description of these technologies. Having such documentation available could be helpful to gaining acceptance and, ultimately, deployment of new technologies.

\section{Current Context}

Other renewable energy communities, notably wind and solar, disseminate useful, well-written technology white papers and other public documents that provide easily understood technology information. The hydroelectric industry could benefit from being more proactive in disseminating information, especially about newer technologies.

\section{Vision}

White papers are routinely prepared and focused on specific new technologies. Documentation of successful implementations is widely disseminated to inform the public, agencies, and the engineering and financial communities regarding the robustness of the technologies and lessons learned during deployments. These papers assist earlier adoption of new technologies and this, in turn, helps accelerate their acceptance and deployment.

\section{Next Steps}

1. Conduct a literature search to aid in identifying suitable topics and seek topics from organizations involved in innovative hydropower technology development.

2. As innovative systems and equipment are deployed, seek information regarding performance and benefits (and needs for improvement).

3. Prepare a list of prospective white paper topics.

4. Engage authors having appropriate backgrounds and experience to prepare white papers on topics of key industry interest.

5. Distribute the completed white papers to appropriate parties to educate them regarding the opportunities and benefits of innovative hydropower technologies. Documents could be disseminated by various means, including making them available via websites, presentations at conferences, and so forth.

6. Consider holding periodic technology roundups. 


\section{Idea 14: Develop a hydropower-specific core education curriculum for hydropower engineers}

Some US universities offer bachelor's degrees that have a renewable energy engineering emphasis; however, hydropower is generally not a focus for these degrees. Rather, dominant renewable energy emphases are wind and solar power. Where universities do offer coursework strongly related to hydropower, it is usually embedded

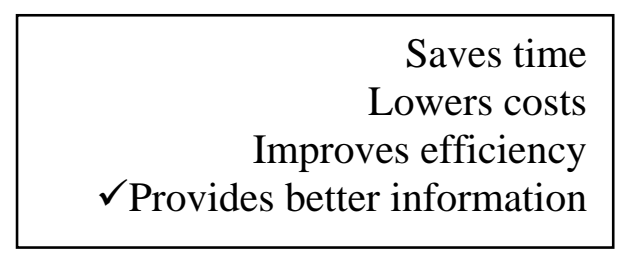
within departments having conventional curricular foci of, for example, civil, mechanical, and electrical engineering. It would be helpful, in preparing engineering candidates for careers in the hydroelectric industry, if universities were persuaded to develop hydropower-specific curricula (for example, they might offer options such as degrees in civil engineering-hydropower option, mechanical engineering-hydropower option, and so on).

\section{Current Context}

Applicable coursework is offered at numerous universities; however, hydropower engineering as such is rarely emphasized. To address needs for hydropower-related education, some organizations have developed stand-alone hydropower courses and online training. Hydropower project owners and consultants often find they must provide extensive on-the-job training to indoctrinate and develop entry-level hydropower engineers, a process that typically takes 3 to 5 years. Although the need for job-specific training cannot be eliminated by university-level education, the quality of training for entry-level engineers could be significantly improved.

\section{Vision}

Core hydropower curricula are developed and made available at several universities for civil, mechanical, and electrical engineers. Courses are developed and delivered both in conventional classroom/laboratory and online formats. When hiring graduates who have met the requirements of these targeted curricula, employers enjoy a degree of certainty about the hydro-related knowledge of newly hired engineers.

\section{Next Steps}

1. Convene a workshop of hiring officials from a broad cross section of the hydropower industry to (1) assess the hiring benefit of having available entry-level engineers already trained in the hydropower specialty and (2) identify needs for the development of hydropower-related curricula.

2. Engage both university and industry personnel to determine the focus of the proposed curricula.

3. Work with interested universities to develop and offer hydropower engineering curricula. 


\section{Idea 15: Develop a training course for small-hydropower operators}

The significant expansion of the development of hydropower projects, especially smaller projects, to capture available waterpower resources suggests that many new hydropower plants will be owned by entities having little or no experience in hydropower operation. It would be helpful to make training available to these new operations personnel.

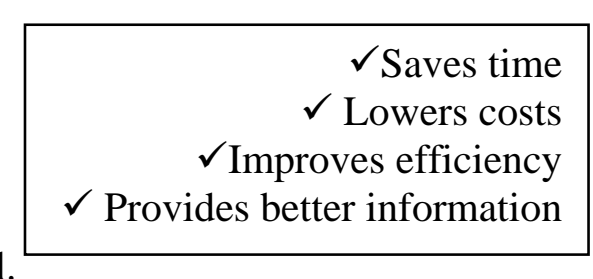
Moreover, owing to the dispersed character of hydropower plants, making training available online could be beneficial.

\section{Current Context}

When new hydropower plants are put into service, manufacturers of the various major systems and items of equipment will typically provide one-time training for personnel. However, this system- and equipment-specific orientation and training does not address overall operations. Usually, experienced personnel must be relied on to develop and initiate safe and reliable operational and maintenance protocols and procedures. There is a dearth of available training specific to hydropower operations, and what is available is often expensive. Moreover, lack of adequate training can expose a plant to costly operational errors.

\section{Vision}

Cost-effective online training for operations personnel is available for various types and sizes of new hydropower plants. Several levels and categories of training are provided, depending on the type of plant and the complexity of operating requirements. In each case, upon successful completion of a rigorous training program, individuals are certified for their level of training.

\section{Next Steps}

1. Interview hydropower owners and operators for different types and sizes of hydropower plants to assess (1) how personnel are currently recruited, developed, and trained to take on plant operational duties and (2) priorities for operations personnel training and certification.

2. Develop a knowledge and skills inventory applicable to personnel for selected operations roles and certification categories.

3. Identify and review available training materials and tools, including online resources.

4. Work with project owners to develop curricula for the tailored training of personnel in various operations categories.

5. Work with training providers to develop needed coursework and evaluation (testing) methods.

6. Offer operations training coursework leading to certification. 


\section{Advanced and Improved Technology, Materials, and Manufacturing}

Use of Advanced Technology, Materials, and Manufacturing

\section{Idea 16: Expand the use of alternative and composite materials in hydropower plant components}

The use of alternative materials, including composites, in turbines, generators, and other hydropower plant mechanical parts could help reduce costs, simplify manufacturing methods, and decrease manufacturing time. Smaller plants, especially, might benefit from using nontraditional materials and manufacturing techniques. The use of alternative and

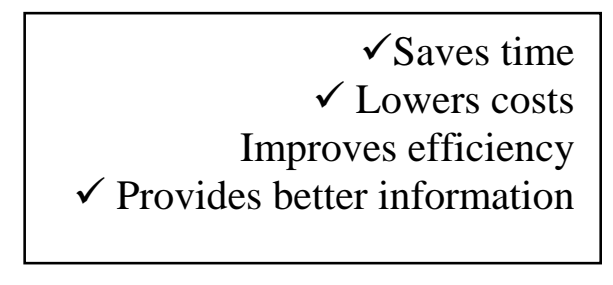
composite materials and other advanced technology may also result in reduced civil costs.

\section{Current Context}

Composite, non-ferrous materials are not widely used in the hydroelectric industry. The turbine, a key component, is usually made of cast iron or steel and, in some cases, stainless steel (or stainless steel overlay). Steel is widely used in other plant systems and components. Although plastics sometimes replace steel in piping and electrical conduits, there has been little use of composite materials.

\section{Vision}

The use of composite materials for small-hydropower plant components enables the use of advanced, additive manufacturing that lowers the cost of components. Component repair and replacement are simplified because of the lower weight of the composite parts. In some cases, composite components have shorter lives than the steel-based counterpart; however, low cost and simplicity of production leads to lower overall costs. Among the alternative and composite materials available for use are the following:

- Ceramics are beneficial because of their toughness, dimensional stability, and receptiveness to computer-generated printing techniques

- Thermoset plastics are beneficial for their light weight and because they can be reinforced into Fiberglas through the use of borosilicate glass or carbon fibers. Fiberglas can be laid-up over standard forms; high heat requirements and extensive welding can be avoided.

- Thermoform plastics, easily formed by heating and mold forming or by machining, are beneficial because of their ultra-low cost.

- Sintered metals and ceramics enable the production of modestly sized parts using lasers and three-dimensional printing methods.

- Sandwich composites use lightweights core or honeycombs (perhaps printed with threedimensional techniques) coated with abrasion-resistant surfaces.

- Advanced sensors for condition monitoring and control of equipment are embedded within composite components. 


\section{Next Steps}

1. Fund research in the use of advanced materials.

2. Contact organizations having experience with pumps, pump impellers, and nautical propellers to learn of experience with alternative materials, especially composites; ascertain whether the extant experience indicates a potential for use of alternative materials for turbine runners (especially for small turbines).

3. Undertake demonstration projects to show the merits of using nontraditional materials. Widely publicize beneficial outcomes. 


\section{Idea 17: Develop strategies for smaller and reduced reinforced-concrete structures}

The civil construction of a hydropower plant- the placement and erection of concrete and steel-typically is by far the largest project cost. The civil construction encompasses the dam, powerhouse, and major water conduits that direct water to and away from the hydropower turbines. In smaller projects, the construction cost can be as much as two-thirds of the total

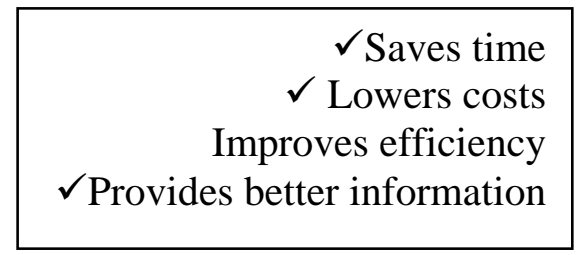
project cost; in larger projects, it can approach as much as $90 \%$. Small reductions in quantities can result in large savings in cost and schedule. Management of this part of the project often can determine whether a project is economical.

To reduce civil construction costs, new strategies are needed to reduce the size and erection costs of concrete components, concrete walls, and the like (Figs. 4 and 5). Smaller, thinner structures need to be investigated toward accomplishing the same purposes safely and reliably. The use of alternative materials should be explored for cost saving potential, as should post- and pre-tensioning and geomembranes, as ways to reduce the quantities of traditional steel-reinforced concrete needed.

\section{Current Context}

Construction codes are specific for the design of concrete, reinforced concrete, and steel components. Strategies are not standard for smaller and reduced quantities within reinforced concrete structures. There have been some advanced material innovations, such as fiber-reinforced concrete, roller compacted concrete, and various concrete additives. Nonetheless, the

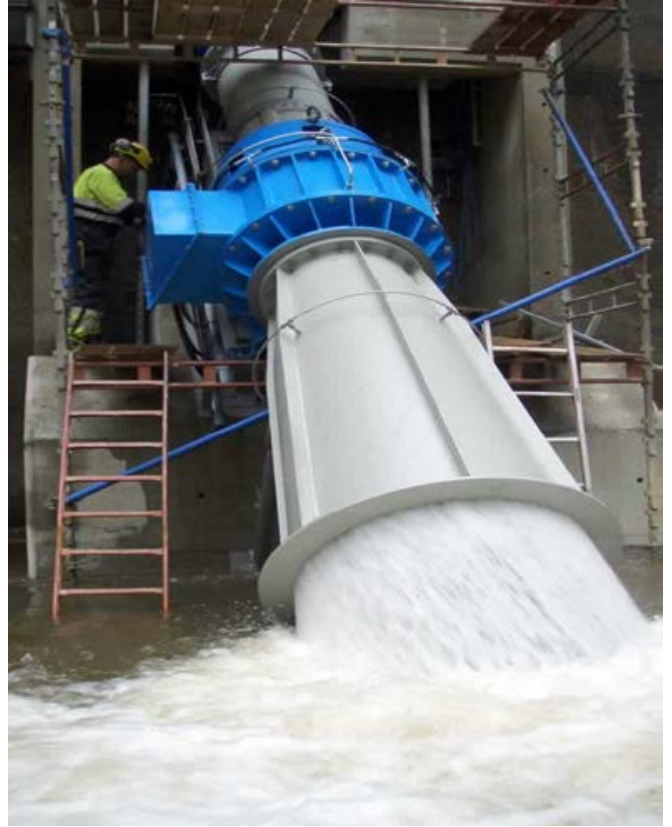

Fig. 4. No powerhouse is required for this unit, which reduces costs.

overall quantities of concrete used for hydropower projects and related structures have not been reduced significantly over the last 20 years.

\section{Vision}

Modularization and standardization allow the use of precast concrete (a standard time- and costsaving approach). New equipment designs allow structures to be reduced. With reductions in the size of equipment and systems, powerhouse and equipment galleries can be reduced in size or eliminated entirely, ${ }^{17}, 18$ making a powerhouse unnecessary. Improved approaches to designing intakes, waterways, and powerhouses reduce cost, improve constructability, and reduce construction schedules. Civil construction costs are being reduced by the increasing use of

\footnotetext{
${ }^{17}$ http://www.nordicgreen.net/startups/article/norway-s-cleanpower-install-three-1mw-turbinator-hydropower-turbinesoregonPhoto: Mats Renvall, January 9, 2012

${ }^{18}$ http://voith.com/en/products-services/hydropower/streamdiver-55362.html
} 
submersible equipment, which operates underwater; when maintenance is needed, the equipment is simply raised above the water level.

\section{Next Steps}

1. Identify methods, equipment, and systems that will reduce the requirements for placement of steelreinforced concrete.

2. Explore the use of alternative waterproofing materials (rather than relying on concrete to provide waterproofing) to save on civil construction costs. For example, membranes have been used effectively to simplify and reduce

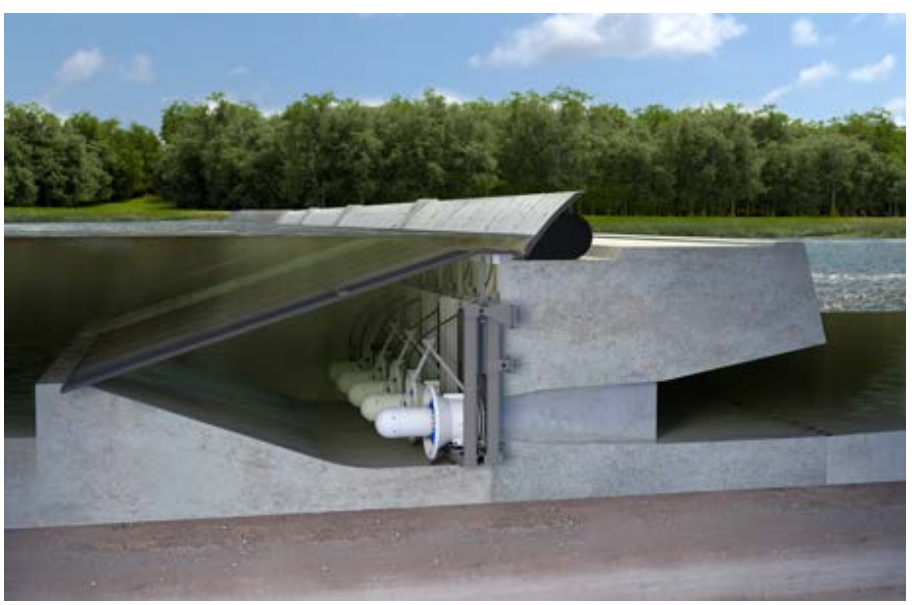

Fig. 5. The pictured structure is a compact turbine for lowhead applications that can be integrated into existing weir systems or transfer structures to minimize civil construction. It has water-lubricated bearings and standardized frame sizes. the cost of dam construction. Explore additional opportunities for cost-saving through using membranes or other waterproofing (e.g., spray-on liners) in other areas of the hydropower plant structure.

3. Examine whether composite materials offer opportunities for wholly or partially replacing reinforced-concrete structures to save cost.

4. Examine the reasons behind current practices, e.g., engineering codes and standards, standard design practices. Explore whether there is opportunity for more intelligently designed structures that are more economical.

5. Prepare case studies comparing the results of using traditional structural engineering and engineering codes versus using modern civil engineering techniques and strategies that result in reducing the quantities of concrete used.

6. Establish a working group that focuses on reducing hydropower plant civil construction costs. The group could engage project designers, construction contractors, universities, and laboratories in developing lower-cost methods that advance hydropower construction. 


\section{Idea 18: Develop new turbine technology to reduce or eliminate civil construction}

The physical relationships between the turbine generator (or pumped turbine motor generator) and the powerhouse and other civil structures are well understood. New turbine technology is under development that reduces or eliminates the traditional powerhouse and simplifies civil construction. It is critical to encourage these new technologies in order to provide innovative solutions for new small hydropower.

\section{Current Context}

New turbine technologies are being developed that allow the elimination and/or reduction of some aspects of civil construction (e.g., see Fig. 6). Some promising technologies are Mavel siphon turbines and other standard small-hydropower turbines, Stream Diver (Voith), Turbinator (CleanPower Norway), Canadian Hydropower Components standard-size axial flow and Francis turbines, Natel HydroEngines, Instream Energy Systems turbines, AMJET turbines, Canyon Turbines, and Obermeyer matrix turbine, among others. These new technologies have the potential to lower capital costs and shorten construction schedules.

\section{Vision}

Innovative technology has been tested and proved reliable and safe. The new technology reduces costs by significantly reducing the associated civil construction and simplifying equipment designs.

\section{Next Steps}

1. Grants and Prizes. Encourage, through grants and prizes, continued innovation of new, improved hydroelectric equipment to highlight achievement and innovation in

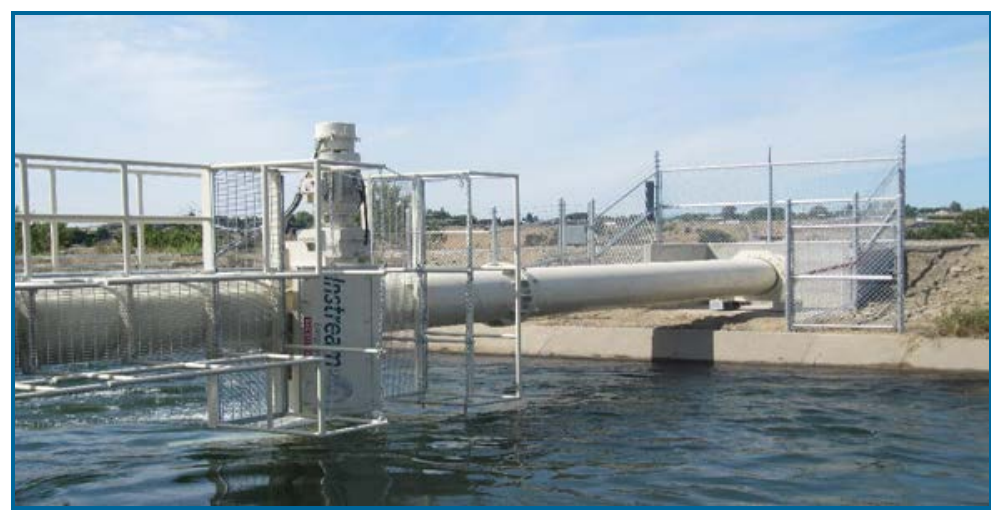

Fig. 6. This ultra-low-head pilot project with limited civil works (no dam, penstock, drop, or weir required) was deployed at the Bureau of Reclamation Roza Canal on the Yakima Project in Washington. The design spans the canal, which prevents contact with the canal lining and limits waterway interactions.

http://instreamenergy.com/projects/yakima-washington/ reducing or elimination civil construction requirements.

2. Case Studies. Prepare and widely distribute case studies of successes and failures and information about promising technology, advanced materials, and equipment and system developments that could enhance hydroelectric equipment. The target audiences would be engineers, financiers, agencies, and developers.

3. Prototype Installations and Test Beds. New, innovative hydropower technology often is prohibited from moving from concept to demonstration because of a lack of sites where innovative principles and technologies can be shown to have merit. Establishing suitable test sites could be extremely beneficial to the development of new technology that reduces or eliminates requirements for civil construction. ${ }^{19}$

\footnotetext{
${ }^{19}$ Owing to FERC's creation of a special exemption to normal licensing requirements, Verdant Power was able to operate, solely for purposes of testing, its East River stream power facility in New York City. Absent this exemption, Verdant Power would have
} 


\section{Idea 19: Accelerate three-dimensional printing of turbines and components}

New three-dimensional additive manufacturing techniquesgenerally referred to as "three-dimensional printing" —are rapidly evolving from the realm of novelty to practical applications. Small hydropower may be an area where this new technology can be beneficially applied. Threedimensional printers are becoming larger and more capable

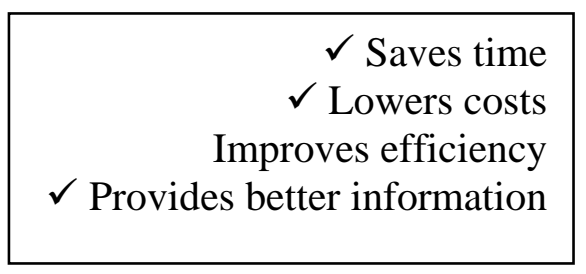
and have the potential to become powerful producers of mid-size parts. Prospectively, these capabilities could be applied to producing small-hydropower turbines and other components needed for a small-hydropower plant.

\section{Current Context}

Currently, most hydropower equipment is manufactured in traditional factories. Although in the past some small-hydropower equipment has been produced in small workshops, that is rarely the case today. Project components are often steel or stainless steel, shaped using computer-aided equipment, e.g., plasma or water jet cutters. Welding is usually (although not always) done manually. The advent of three-dimensional printing may offer the opportunity to move to better, less expensive hydropower component manufacturing (and less prone to human error).

Three-dimensional printers currently available use additive methods to follow computer instructions to precisely place materials to build up an item. The materials used may be plastics (e.g., photopolymers, films, thermoplastics), metals (e.g., powders, foils, alloys of aluminum, steel, and other metals), and ceramic powders. The most advanced printers can place advanced metals such as cobalt, chrome, and titanium, albeit with greater expense.

This new technology is already having an effect: General Electric, a large turbine manufacturer is currently applying a high-end three-dimensional printer to the production of complex molds needed for casting certain gas turbine runners. ${ }^{20}$ ORNL is partnering with Cincinnati Incorporated to develop a large-scale polymer additive manufacturing (three-dimensional printing) system that is 200 to 500 times faster and capable of printing polymer components 10 times larger than today's common additive machines-in sizes greater than one cubic meter and large enough for printing of small hydropower machine and structural components.

\section{Vision}

Three-dimensional printers are routinely used to quickly produce components of small-hydropower plants at low cost.

\section{Next Steps}

1. Convene a meeting of individuals and experts who have knowledge of and experience with three-dimensional printing, as well as experience in building micro-hydropower equipment and plants. The purpose is to discover prospective opportunities for applying threedimensional printing to produce hydropower plant parts and components. For the benefit of

\footnotetext{
been unable to perform testing essential to demonstrating project feasibility. This is a rare example where a regulatory agency cooperated to enable a RD\&D (research, development, and deployment) related activity.

${ }^{20}$ http://www.gereports.com/post/74545205358/supersize-me-ge-takes-3d-printing-to-massive-gas
} 
the industry, publicize the results of this meeting. Depending on the opportunities discovered, plan subsequent related activities.

2. Establish competitions or prizes for individuals who demonstrate the application of threedimensional printing to devices for hydropower production. (This effort could perhaps be modeled after the former Hydropower Contest, which engaged both university students and practicing hydropower professionals.) 


\section{Idea 20: Establish specifications, criteria, and validation methods for fish-friendly turbines}

Hydropower turbines that reduce injuries to fish became a hydropower industry focus in the mid-1990s when the industry and DOE collaborated to develop new turbine technologies that could be used to pass fish through turbines with minimal adverse effects on the fish. As a result of a long-term industry and DOE collaboration, important technological advances were made, new turbines were developed and installed in large hydropower facilities, and the term "fish-friendly" became part of the hydropower vernacular. However, only one turbine manufacturer has installed fish-friendly turbine equipment that has undergone field validation of fish-passage performance.

As new turbine designs are marketed by a variety of manufacturers as fishfriendly, prospective purchasers of this equipment must have a means to specify fish-passage performance and cost-effective methodologies for validating that performance.

Independent testing and verification of fish passage performance and outcomes will likely be a prerequisite for environmental stakeholder acceptance of fish-friendly turbine installations. Research is needed to advance the science of evaluating, modeling, and projecting fish behavior, injury, and mortality during turbine passage and to integrate that science into turbine procurement, design, and performance validation. Successful deployment and validation of fishfriendly turbines could reduce project costs and mitigation costs by eliminating the need for fish screens and other fish guidance structures or barriers.

\section{Current Context}

The body of knowledge on fish behavior, injury, and mortality during downstream turbine passage_-including data and findings from computational, laboratory, and field testing — is centered on salmonids passing through large turbines. Low-cost turbine technologies, existing (Fig. 7) and future, from a variety of
The hydropower industry, under the auspices of the Hydro Research Foundation, joined DOE and other federal agencies in an accelerated research and development program to create a new generation of fish-friendly hydropower turbines. These turbines could minimize impacts to aquatic life in rivers while providing a more economical energy supply by increasing hydropower plant efficiency. In 2009, DOE funded the Electric Power Research Institute to continue development of the Alden fish passage turbine design for eventual deployment on a commercial scale. DOE funding enabled testing and developmental engineering at the Voith test facility. The results from the trials exceeded expectations: at peak performance, an Alden turbine can convert about $94 \%$ of the water's energy into usable electricity; that is comparable or superior to the efficiency of traditional turbines. The overall wildlife survival rate should be over $98 \%$, up from $80-85 \%$ for a traditional turbine. ${ }^{1}$

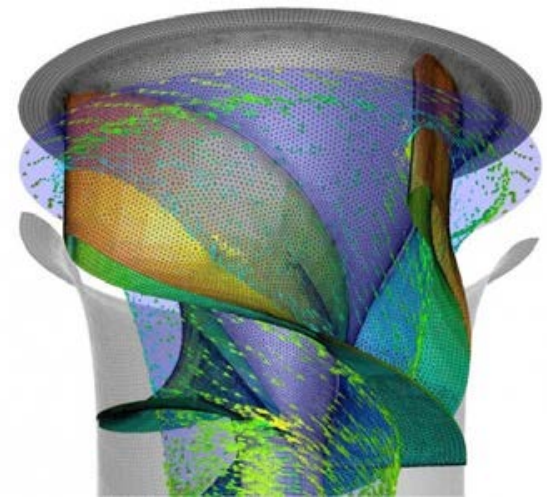

http://energy.gov/articles/fish-friendly-turbine-making-splash-waterpower 
manufacturers will need to be designed and validated as fish-friendly for many fish species of concern, including salmonids and eels.

\section{Vision}

Research has established parameters for turbine fish-friendliness for a variety of operating regimes, locales, and species. Ongoing research is conducted to ascertain the ability of turbine technologies to permit fish passage, and new turbines-some with relatively minor adaptations of prior technology — are demonstrating fish-friendly characteristics and entering the marketplace.

\section{Next Steps}

1. Establish a research activity or competition that outlines the essential requirements for turbine fish-friendliness

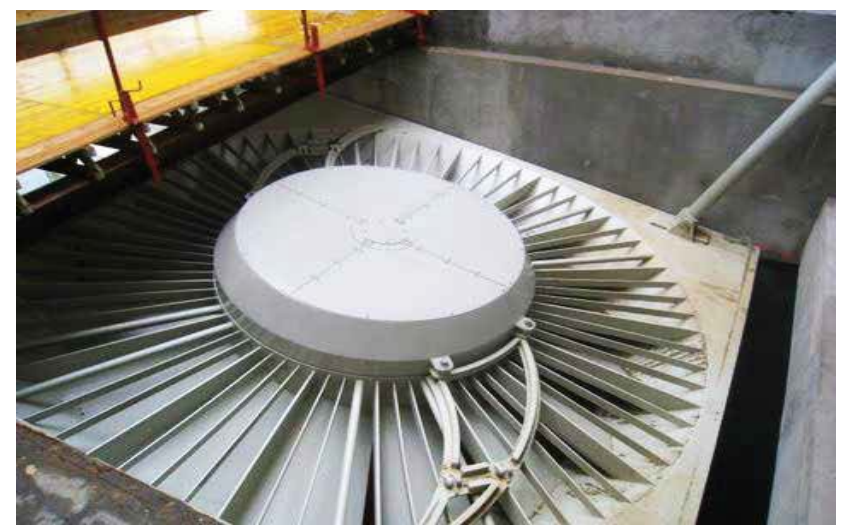

Fig. 7. Early testing of the VLH MJ2 turbine indicates the design is promising for eel passage. based on the flow regime (head, flow) and the fish/aquatic species that need to be protected.

2. Employ researchers to establish a means of appraising new and developing turbine technology to assess fish and aquatic life passage and survivability.

3. Engage industry personnel to establish guidelines and research objectives and to review the research outcomes. 


\section{Idea 21: Stimulate technology innovation relevant to new hydropower}

The hydropower industry traditionally has focused on wellestablished, long-lasting technology. The impetus to lower costs and reduce the time required to deploy a project suggests there should be opportunities to encourage new technology by encouraging new engineers and scientists to focus on innovations that are applicable to new projects that address today's priorities and issues.

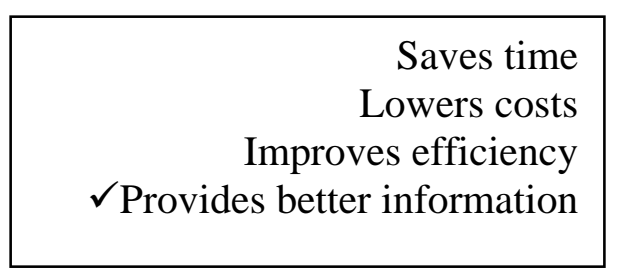

\section{Current Context}

Various methods are being applied for stimulating technological innovation. These methods depart from the traditional laboratory settings of the past. Instead, today, it is common for talented, well-educated young people to be attracted to technology incubators. The incubation approach is technology neutral - it is widely applicable to an almost unlimited range of technological pursuits.

One recently launched incubator approach is that of the "makerlab." One description of this approach is that "MakerLab is an open discussion powered by prototyping and making." 21 There is, in fact, a "maker movement" under way. Make magazine and the events it sponsors called "Maker Faires" are part of this trend. ${ }^{22,23}$

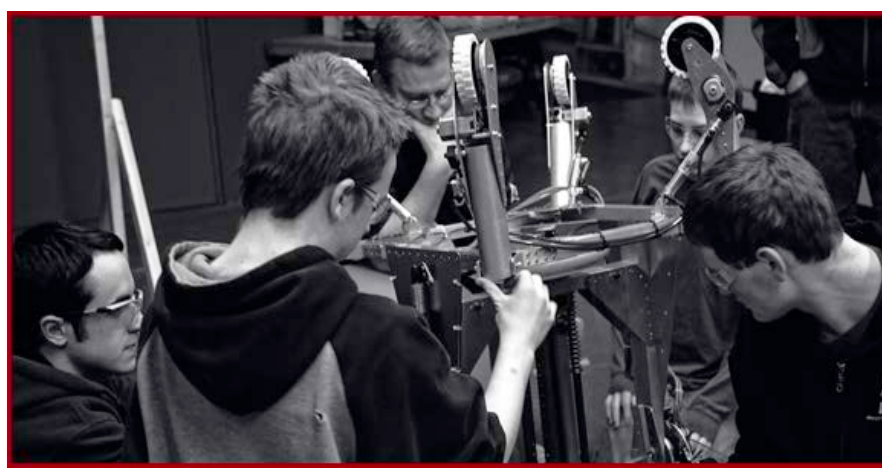

Several organizations recognize significant technology implementations. The National Hydropower Association

Gizmo CDA is an example of a locally established community makerlab in Couer d'Alene Idaho. does so each year in granting its Outstanding Stewards of America's Waters Awards. DOE has sponsored several renewable technology competitions, although there is no hydropower technology-specific competition to recognize best-in-class emergent technologies.

\section{Vision}

A collaborative, interactive makerlab network engages young scientists and engineers to work on applied research related to new hydropower. Annual competitions recognize the best new technologies that come from these individual efforts. Other avenues for stimulating advancements in hydropower are being actively pursued.

\footnotetext{
${ }^{21}$ http://www.makerlab.info/sample-page/

22 http://www.gizmo-cda.org

${ }^{23}$ Information on Make magazine available at http://makezine.com
} 


\section{Next Steps}

1. Create a Hydropower Makerlab Network

a. Survey existing technology incubators, focusing on makerlabs.

b. Convene an interactive workshop to brainstorm what the charter and characteristics would be for a makerlab network and compare those with available facilities.

c. Identify topics of interest to be addressed via the network and provide a "hydropower kit" to the network.

d. Contact universities with a demonstrated commitment to hydropower to solicit interest in implementing a hydropower makerlab. Pair interested universities, agencies, and industry members with the network of makerlabs.

e. Create a hydropower technology competition. Convene a small group of industry experts to develop parameters for the competition. Develop a proposal for the competition and secure funding.

2. Establish Centers of Hydropower Excellence-Centers of excellence could provide promising engineers, scientists, and inventors with opportunities to work on and advance novel and prospectively beneficial ideas. Establishing fellowships or residencies (e.g., for 2 years) could be beneficial. These centers should provide access to skilled craftsmen, computers, tools, and advanced materials for developing models and prototypes and conducting computer simulations. They should be seen as places where trial and error is acceptable and innovation is encouraged..

3. Create a Hydropower Innovation Council-A council consisting of senior industry leaders could identify, encourage, mentor, and foster the next generation of hydropower inventors and innovators. The council could include academics, practicing engineers, inventors, patent holders, thought leaders, and other professionals who have demonstrated a passion for both hydropower and innovation. (The council could serve-with a hydropower focus -in a role analogous to those of the national academies of science and engineering, which focus broadly on matters of science and technology that are of national interest. Fellowships and research awards could perhaps be established by the Hydro Research Foundation with the involvement of the council.)

4. Create a Technology Review Program-Diverse technologies are greatly intertwined today and often a scientific or technological advance in one area finds application in another. For hydropower, the process could be beneficially enhanced by the continual purposeful surveying of science and technology to discover areas in which further investigative, research, and technology development efforts might prove fruitful. Although R\&D needs surveys have from time to time been undertaken in the hydropower industry, these typically have involved only individuals who are already embedded in the industry, who likely will not possess knowledge relevant to many areas of science and technology that could benefit hydropower. Periodic, broadly focused reviews could be advantageous. 


\section{Standardized and Modular Designs}

\section{Idea 22: Develop standard designs for conduit hydropower}

Existing water conveyance infrastructure includes canals and pipelines. Appropriately sized standardized designs of hydrokinetic, micro-hydropower, and small-hydropower facilities could enable much greater capture of energy that is currently wasted. Simple, standardized, off-the-shelf designs that have proved to be reliable and that can be easily and quickly installed would be attractive to hydropower operators. The owners and operators of these facilities are primarily interested in the reliable delivery of water, e.g., for municipal supply or irrigation, and want to avoid any risk of disruption of water delivery.

\section{Current Context}

A variety of project designs have been built on canals and pipelines. Untapped canals and pipelines provide immediate opportunities for the rapid deployment of small-hydropower installations. Standard designs could facilitate acceptance and deployment.

\section{Vision}

A limited variety of standard micro-hydropower and small-hydropower plant designs have led to wide deployment on water conveyance systems. A library of standard designs is available on the web, which can be used by conduit owners and third-party developers. This web-based information includes installation case studies, physical arrangements, equipment and cost information, lessons learned, and best practices.

\section{Next Steps}

1. As a key resource, identify design leaders with experience in water conveyance energy capture projects.

2. Develop a catalog that provides information about recently developed water conveyance energy-capture projects.

3. Gather manufacturer/supplier information on hydrokinetic, micro-hydropower and smallhydropower equipment and installations.

4. Develop a plan to address technology gaps and, where appropriate, to promote these types of installations to prospective beneficiaries. 


\section{Idea 23: Develop standardized, factory-assembled small-hydropower equipment packages with ancillary equipment mounted on skids to speed construction}

There appears to be an opportunity to advance smallhydropower technology — especially in terms of costs and construction time-by developing more standardized, integrated, and complete water-to-wire equipment packages. The availability of prepackaged plants could facilitate more rapid deployment of new small-hydropower

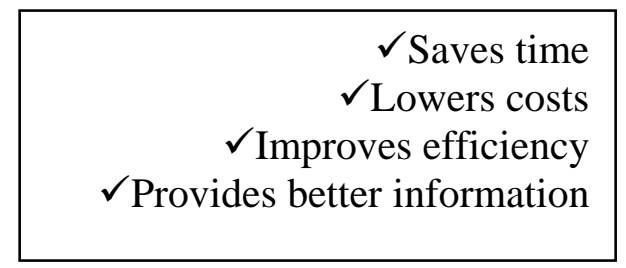
projects by reducing costs, schedules, and development and financial risks.

\section{Current Context}

Complete predesigned, adaptable water-to-wire equipment packages are not currently available in the hydropower marketplace. (Some partial equipment packages are available that approach this ideal.)

\section{Vision}

Standardized water-to-wire equipment packages are commonly available for most smallhydropower applications. These include factory-assembled turbine-generator packages, mounted on single skids, requiring minimal onsite installation work. Factory-assembled packages also provide electrical and control systems and, as needed, hydraulic, compressed-air, and other systems. On-site civil construction work is minimal, and the installation of the factory-built packages (on pre-constructed foundations) requires relatively simple on site bolt-up, welding, and/or concrete placement. Most system checkouts are accomplished in the factory, and only final verification checks are required on site.

\section{Next Steps}

1. Work with manufacturers to assess what sizes and types of small-hydropower installations it would be most advantageous to pursue to realize the benefits of standardized hydropower equipment packages.

2. Identify several existing small-hydropower installations to examine "what if" assessments. For example, what if standard factory-assembled packages had been available for the construction of these plants? How beneficial would that have been, i.e., how much project cost and time savings would have been likely?

3. Explore whether using standard pre-assembled equipment packages is likely to expedite obtaining necessary licenses and approvals (e.g., from FERC). For example, would using standard packages be beneficial in obtaining Low Impact Hydropower Institute certification?

4. Based on the outcome of this initial investigation, ascertain what further study in this area is warranted. 


\section{Idea 24: Simplify project operations and maintenance by using modular components}

In other industries, standardization and modularization have been shown to lower maintenance costs and reduce the time a piece of equipment is out of service.

\section{Current Context}

The airline, computer, and automotive industries have adopted an approach to equipment design that entails using plug-in modules that make up a piece of equipment. When a piece of equipment requires maintenance or replacement, a new module replaces the worn or defective module and the equipment is quickly placed back into service. The equipment removed can be refurbished off line and re-used, or discarded if that is more cost effective. There is less chance of error since the replacement process is well understood. Modular manufacturing has also been demonstrated to improve the quality of manufacturing, fabrication, and construction.

Although this practice is not widely used in hydropower, some equipment suppliers are approaching unit designs with an eye to making portions of the turbine generator so that they can simply be lifted out of the unit and replaced with new components (Fig. 8).

\section{Vision}

Hydropower equipment providers routinely use modular components in the fabrication of a unit, the controls, and the supporting plant systems. System outages due to component replacement are well understood and take minimal time to complete. Case studies of successful use of modular components are readily available. The benefits are well known and accepted by owners.

\section{Next Steps}

1. Compile examples of successful modular designs and installations across other industries and evaluate them for applicability to hydropower.

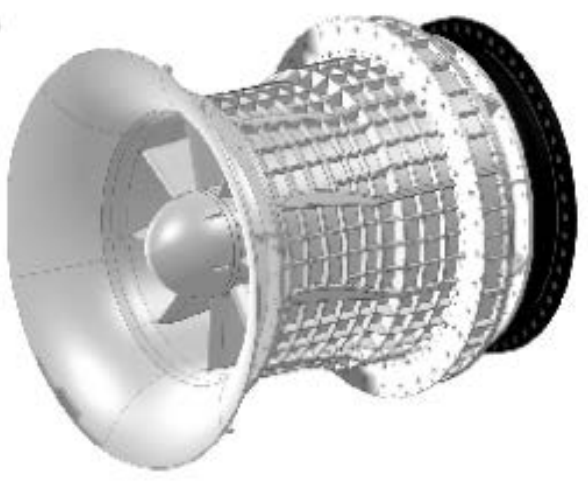

Fig. 8. AMJET is developing a pilot project featuring a lightweight hydropower turbine/generator. The lowweight composite components are designed for simplicity of installation, maintenance and repairs.

2. Compile examples of successful modular designs and installations in hydropower equipment.

3. Assess existing and new equipment technologies as to their suitability for modularized deployment and maintenance.

4. Encourage a modular approach to operations and maintenance in hydropower by establishing pilot projects to explore the efficacy.

5. Conduct a workshop at one of the annual hydropower events in which modularization is discussed and examples and concepts add to the information being collected.

6. Consider holding a contest for modular plant design and maintenance. 


\section{Idea 25: Develop a library of three-dimensional drawings and configurations}

An Internet-accessible library of standard threedimensional small-hydropower configurations could enable developers and engineers to more easily obtain information from equipment suppliers early in the process of project development. The ready availability of this design information, in this form, could reduce the time and costs of preliminary engineering at a critical early stage in the of the development process and provide a greater level of detail than is typically available. This could enable better assessments of environmental (and other) consultation requirements. In addition, the greater detail could be helpful in facilitating financing arrangements or partnerships. Moreover, owing to the use of standard formats and configurations, equipment supplier responses-which require speculative investments of time and effort—would be simplified.

\section{Current Context}

Most information provided to developers by equipment suppliers is furnished by letter, in text and tables, and via two-dimensional drawings. (Moreover, drawings are not readily convertible to a three-dimensional format.) Suppliers are usually inundated with requests for information from prospective developers and equipment purchasers; and they tend to be selective, responding to projects with which they are most likely to be successful. And although they may want to be helpful, they rarely have the resources to provide three-dimensional information before making a formal quotation, i.e., quite late in the project development cycle.

\section{Vision}

Standard three-dimensional small-hydropower plant and equipment configurations are available online. These configurations allow developers and their engineers to quickly develop preliminary designs, and they enable equipment suppliers to easily respond to requests for information.

\section{Next Steps}

1. Perform a worldwide survey to ascertain whether practices are being used regarding drawing supplies that are worth emulating.

2. Interview equipment manufacturers to get their input regarding suitable parameters for the content of the online library.

3. Interview developers regarding what information they would find most helpful.

4. Based on the responses to these surveys, develop and launch a prototype "small-hydropower configurations" website. 


\section{New and Improved Electrical Standards and Practices}

\section{Idea 26: Develop standard electrical and control configurations for new hydropower plants}

New plants now have electrical and control configurations that are customized to each plant based on the owner/operator requirements. The electrical and control aspects should be more standardized and modularized to achieve lower costs.

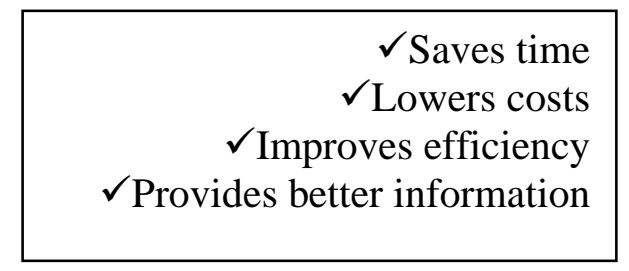

\section{Current Context}

Presently, too much customization is needed for electrical systems and controls for micro, small, and conventional hydropower. Most of these new plants are fairly simple and are unstaffed when placed into operation. But even hydrokinetic and micro-hydropower plants do not have standard electrical and control configurations. Standard configurations are necessary for reliability, safety, reduction of cost and time, for installation and commissioning. This lack of standardization is often typical of a period of inventions and early adoption but is not typical of a market as mature as hydropower.

\section{Vision}

The next generation of micro, small, and conventional hydropower plants have standardized electrical and control systems based on equipment rating and system characteristics. These systems are operable remotely.

\section{Next Steps}

1. Encourage or incentivize the Institute of Electrical and Electronic Engineers (IEEE) and the electrical equipment/controls industry (manufacturers and integrators) to standardize and modularize hydroelectric electrical and control equipment components. Such an effort could reduce the overall cost and the manufacturing time for critical components. Standardization and modularization should allow components to be more readily manufactured and improve their availability. Doing so will increase the availability of spare and replacement parts and reduce the cost of operations and maintenance.

2. Support the charter of an IEEE working group supported by the Hydroelectric Subcommittee to work on these standards. The electrical/controls industry should be able to standardize around certain basic plant criteria associated with control and protection philosophy and voltage, frequency, and amperage requirements.

3. When the standards are completed, widely publicize their availability at industry conferences and workshops. 


\section{Idea 27: Develop standard substation configurations}

There are standard substation configurations, but they vary from utility to utility. Having readily available standard designs for use with hydroelectric applications would decrease design time and lower costs.

\section{Current Context}

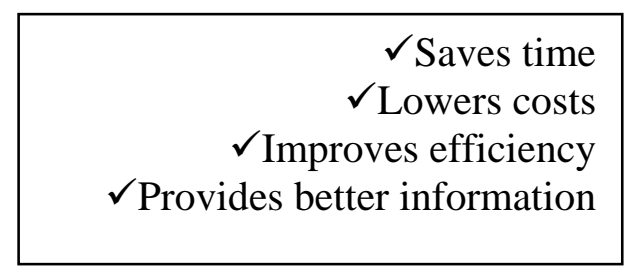

Several manufacturers offer predesign and standard substation configurations. These have demonstrated lower cost and more rapid substation installation.

\section{Vision}

Most substations are predesigned and have standard and modularized components. High voltagesubstations may still require a custom design. However, based on the early adoption of lowvoltage predesigned modular substations, even predesigned high-voltage substations can be developed. There are rare circumstances in which customization is needed, but they are no longer the norm.

The use of predesigned standard and modular substations is the industry standard. Competition sets the prices for predesigned substations and shortens the concept-to-commissioning construction schedules.

\section{Next Steps}

1. Encourage IEEE and the electrical equipment/controls industry (manufacturers and integrators) to standardize and modularize substation electrical and control equipment components. Such an effort could reduce the overall cost and the manufacturing time for critical components. Standardization and modularization should allow components to be more readily manufactured and improve their availability. Doing so will increase the availability of spare and replacement parts and reduce the cost of operations and maintenance.

2. Support the charter of an IEEE subcommittee to work on these standards. The electrical equipment/controls industry should be able to standardize around certain basic plant criteria (associated with control philosophy, voltage, frequency, and amperage requirements.

3. When the standards are completed, widely publicize their availability.

4. Provide training to allow the adoption of predesigned substations with modular and standard arrangements. 


\section{Idea 28: Develop small-hydropower standards for the National Electrical Code}

Developers of micro-hydropower and small-hydropower projects frequently encounter reluctance to accept custombuilt electrical and control equipment that is not product listed under the National Electrical Code. As a result, developers sometimes encounter difficulties in obtaining acceptance for interconnection. Such issues require redesign, adding cost and delaying schedules. Supporting a process to develop small-hydropower standards for incorporation into the 2017 update of the National Electrical Code could be helpful.

\section{Current Context}

Practical standards are not in place that address the need to achieve both safe and reliable interconnection at reasonable costs. However, work in the wind industry provides a good example of successful cooperation to resolve interconnection issues. By working with the electrical equipment and controls industry and IEEE, the wind industry put in place appropriate electrical and controls standards. As recently as the 1990s, wind electrical and control equipment and systems did not comply with product listing and certification requirements. This often presented challenges during electrical inspections and could lead to large costs to meet requirements imposed in the field-requirements that must be met to gain inspector approval. Similar issues can have substantial adverse effects on the economics of small-hydropower installations. The wind industry's approach was to prepare a revision in the 2011 electrical code that eliminated the listing requirement for small inverters. This exemption-from-listing approach could perhaps be applied to certain aspects of small-hydropower equipment.

\section{Vision}

Micro-hydropower and small-hydropower interests have worked with the IEEE and the electrical and controls industry to develop micro-hydropower and small-hydropower standards and recommendations (e.g., for certifications) suitable for incorporation in the 2017 update of the National Electrical Code.

\section{Next Steps}

1. Work with the IEEE Hydropower Subcommittee to address needs for appropriate standards and certifications for micro hydropower and small hydropower with respect to electrical and control features and interconnection criteria.

2. Prepare suitable changes and work for their incorporation in the 2017 update of the National Electrical Code. 


\section{Idea 29: Develop and promote standard interconnection methods and standards for small-hydropower and micro-hydropower installations}

Small-hydropower and micro-hydropower installations typically must connect to a transmission or distribution grid to deliver the electricity produced. Interconnection standards, methods, and requirements vary widely.

\section{Current Context}

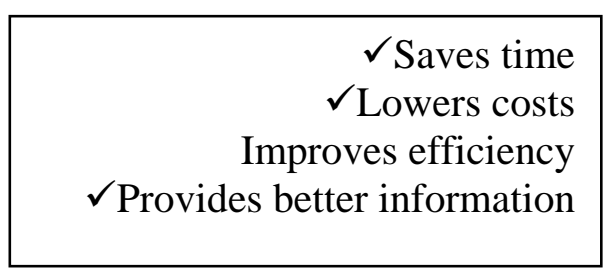

Presently the requirements applicable to micro-hydropower and small-hydropower project electrical interconnection vary widely. The requirements are typically established by the interconnected entity, the recipient of the electricity. Recipients may be investor-owned or public utilities, municipalities, and the like. Owing to the relatively small scale, interconnection to a distribution (rather than transmission) system is often possible. One common problem is that interconnection requirements for small projects may be the same as for large power generation projects, irrespective of the technical necessity. This can cause sizeable delays — and large costs - that could be avoided with some standardization. PJM Regional Transmission Organization has issued interconnection-wide standards.

\section{Vision}

Sensible, technically valid interconnection requirements for small hydropower and micro hydropower have been developed and are widely embraced.

\section{Next Steps}

1. Survey methods of interconnection used by wind and solar energy companies to ascertain whether their

PJM Small Generator Technical
Requirements and Standards apply
to units of $10 \mathrm{MW}$ and below. They
requirements within PJM with IEEE
standards and facilitate the pre-
certification of manufactured
generation and equipment and
systems for use with in PJM.
http://www.smeco.coop/documents/pj
m-manual-14b-attachment-h.pdf
practices may have beneficial application in the hydropower sector.

2. Survey the interconnection requirements, practices, and experience of existing smallhydropower and micro-hydropower installations to establish a baseline of information.

3. Survey the interconnection requirements of the regional transmission organizations.

4. Work with the IEEE Hydropower Subcommittee to develop best practices interconnection requirements for small hydropower and micro hydropower.

5. Formalize recommended best practices for a range of small-hydropower and microhydropower installations that address the concerns of both electricity-receiving utilities and small- and micro-hydropower producers.

6. Seek to gain adoption of the best practices by receiving utilities. 


\section{Idea 30: Explore expanded use of net metering in small-hydropower and micro- hydropower applications}

Net metering (also referred to as net electricity or net energy metering) is an arrangement that enables electricity customers who supply part of their electricity from onsite generation to pay only for the net amount of electricity that they obtain from an interconnected utility. Net metering came into use primarily to promote investment in

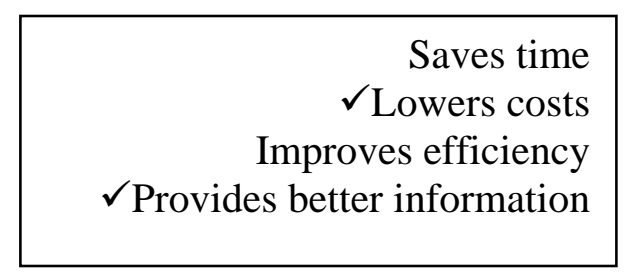
renewable energy, especially solar. Rooftop solar installations largely rely on net metering arrangements. ${ }^{24}$ Net metering programs have been established in most US states.

\section{Current Context}

Small-hydropower installations rarely make use of net metering arrangements. However, prospectively, such arrangements could be beneficial. Where it is implemented, net metering allows the onsite power producer to gain greater value from the electricity produced. Although arrangements vary, a common plan enables the producer/consumer, by selling any excess electricity produced, to offset the cost of purchasing needed electricity from the utility at retail rates. The producer/consumer buy only enough electricity to make up for deficiencies from the utility. Although the producer/consumer typically will be a net consumer, it is commonplace for the producer/consumer to receive full credit for electricity production that from time to time is in excess of its needs.

\section{Vision}

As a favored supplier of renewable energy, small-hydropower and micro-hydropower facilities (up to specified capacity limitations) are entitled to enter into net metering arrangements with primary electricity suppliers (e.g., utilities) throughout the United States.

\section{Next Steps}

1. Review and summarize existing net-metering arrangements and their applicability, if any, to hydropower.

2. Interview selected utilities that participate in net metering to obtain their views regarding the arrangements.

3. Develop a strategy to increase the availability of net metering options for small-hydropower and micro-hydropower producers.

\footnotetext{
${ }^{24}$ Cf votesolar.org
} 


\section{Idea 31: Develop best- practices guidance for small-hydropower project commissioning and operation and maintenance plans}

Project commissioning and plans for operations and maintenance often get insufficient attention during the process of developing small-hydropower facilities. It would be desirable to have guidance readily available, including commissioning steps and procedures, documentation needs,

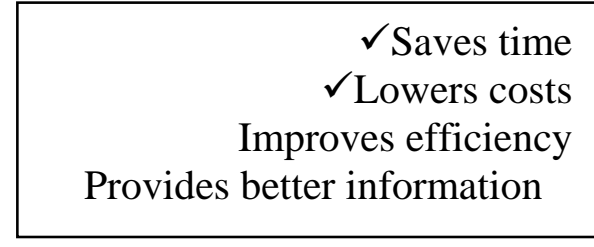

and so on. Although operations and maintenance approaches may vary widely, there is a need to articulate essential elements and describe proven successful approaches.

\section{Current Context}

Plans for project commissioning and for post-commissioning operations and maintenance are a developer responsibility (and cost), but they often get too little attention too late in the cycle of project development. Having best practices guidance available could be quite beneficial.

Plant (or turbine-generator unit) commissioning is typically a joint effort between the vendors and the owner/operator that needs thorough planning. Similarly, long-term operations and maintenance require careful planning. Problems can arise, for example, if equipment supplier operation and maintenance recommendations are not properly factored into the owner/operator management system and budget.

\section{Vision}

Best practices guidance provides small-hydropower project developers, owners, and operators with practical direction for planning and conducting project commissioning activities and for developing and implementing a viable operations and maintenance plan.

\section{Next Steps}

1. Interview the developers of selected recently completed small-hydropower projects to obtain information about their commissioning and operations and maintenance plans; ascertain their lessons learned-additions or changes that would be beneficial.

2. Prepare the scope for developing best practices guidance and undertake efforts to prepare such guidance. 



\title{
Appendix A
}

\section{Compilation of Best Practices Gathered During the Preparation of the Report}

\begin{abstract}
Developing new, small hydropower projects is not merely possible; it is also an attractive way to increase the pool of domestic energy and develop a more robust power supply for the United States. Small-hydropower projects located in diverse locations strengthen the grid by providing consistent, reliable, renewable energy production and voltage support. Small-hydropower projects provide a variety of economic benefits throughout both development and operation. An important question that this report seeks to address is: How can the United States' pace of development of small-hydropower assets be increased? Approaches to small hydropower projects that have been completed - e.g., in the last decade—share some key aspects that have contributed to their success. This appendix identifies some practices that have proven effective toward getting projects built and on line.
\end{abstract}

The following information is not intended to be a handbook of how to develop new small hydropower. It is a compilation of ideas received from the authors during the development of the report that capture their experiences on best practices during particular project phases.

\section{Early Phase Development-Site and Resource Assessment}

Effective site selection is perhaps the single most important aspect in development of a small hydropower project. Investing sufficient time and effort—and bringing to bear appropriate expertise - during the process of site selection is a principal difference between successful and unsuccessful projects. This report suggests that investing more time, attention, and involvement of other interested parties (i.e., stakeholders) at this early stage can save valuable time, effort, and money at later stages of project development, when many more dollars are at stake. Early investigation of key site aspects, along with communication with stakeholders, is one of the least expensive aspects of development and often can be handled in-house by a developer that has a presence in and knowledge of the region. In this stage, there is no substitute for a local presence and field work.

\section{Identification of an Opportunity (Site Analysis-Phase 1)}

Identifying a potential site for development requires early cost/benefit analysis that balances developability with potential production. Use of previously developed resources-especially documentation related to prior FERC licensing activity related to the site-can often be enormously helpful. If applicable, choosing a site that qualifies for a FERC exemption, e.g., sites under $10 \mathrm{MW}$ and conduit options, can greatly simplify the FERC approval process. Exercising a preference for sites that can incorporate low-impact technology and use existing infrastructure or diversions, rather than a new dam, can also be beneficial. While from an engineering perspective the ideal site may be the one with the maximum production and greatest efficiency, environmental and political realities can quickly transform a profitable project into a failed effort. There are numerous examples of projects that failed because of insufficient early research and communication, as issues emerged late in the process. Diligence and thorough, thoughtful communication at the site selection stage can mitigate the potential for unexpected issues that 
can kill a project. At this early stage, a developer needs to establish a thorough understanding of all ownership, environmental, political, or cultural issues that could potentially derail the project. Although there is a balance to be achieved, the need to have a complete understanding of the site should even outweigh the need for project confidentiality. Talking with the right people both locally and at the federal level can pay dividends later on. Those who need to be engaged include community leaders, non-governmental organizations (NGOs; e.g., environmental groups), and permitting agencies. This is the time to bring the hard questions, the prospective problems, to the surface. If there are potential stakeholder issues, establish what they are and be realistic about the ease, or difficulty, involved in addressing them.

Of course, proper engineering is fundamental. It is important that a prospective site be subjected to a thorough hydrological analysis. This investigation needs to include verification and analysis of flow and head data to determine the site's production potential. It is helpful to incorporate low-impact hydropower technology by using an existing infrastructure of diversions or lowimpact, low-head dams. Operation of existing structures and facilities that affect the availability of flow to the project needs careful consideration.

Identification of available financial incentives for the site-such as energy capacity and renewable attributes through renewable energy credits (RECs), local and utility pricing and tariffs, and the likelihood of power purchase agreements (PPAs) - is beneficial at this point in the project.

\section{Suggested Action Steps}

1. Establish a rough layout for the plant incorporating the chosen technology (preliminary engineering), potential production, and potential transmission requirements.

2. Conduct an analysis of obvious, potentially insurmountable interconnection and/or transmission issues. This can be complicated and time-consuming. A developer should anticipate that a year or more will be required to complete this analysis, before which a PPA cannot be obtained. In general, a project will need to participate in an iterative transmission assessment process to determine what, if any, additional transmission charges the project will be required to pay. The good news is that, for small hydropower, the likelihood is low that the additional generation provided will require a transmission line upgrade. However, the developer has little or no control over this process, and it is very unlikely that potential power purchasers will sign a PPA until the transmission charges have been assigned.

3. Identify potential insurmountable environmental, political, or cultural issues.

4. Conduct an early analysis of revenue, including potential buyers, the local/regional market, and current and projected prices.

5. If no issues are identified that could kill the project, file the FERC preliminary permit with the federal agencies or the state/local licensing entity as appropriate. 


\section{Best Practice Methodology for Site Identification}

- Choose a clean site. Avoid sites that have threatened or endangered species and favor sites that have a very low likelihood of requiring fish passage. Identify and seek out sites that will be easy to develop.

- Ensure transparency by connecting with relevant NGOs, agencies, USACE, and community members at the earliest possible opportunity. Developers have found success by working collaboratively early in the process with all stakeholders on noncontroversial sites.

- Focus on attainability over maximization of profit. This might mean choosing Site A (without environmental issues), which might appear upon first analysis to cost more per kilowatt to develop than Site B (with environmental issues). However, broadly speaking, developer experience is that Site A is more likely to be built and will ultimately cost less because of the delays and potential barriers to development associated with environmental issues at Site B.

- Emphasize reliability over hydraulic efficiency (cost minimization over incremental improvements in efficiency). Cost containment includes both initial investment and maintenance costs over time.

- To minimize equipment costs, incorporate best-fit standardized equipment rather than custom equipment that maximizes production from the site. For example, several suppliers have standard turbine sizes, which makes long-term maintenance more costeffective.

\section{Site Viability/Feasibility (Site Analysis-Phase 2)}

With the fundamental hydrology determined; a basic project plan established; a very thorough understanding of the environmental, cultural, and political aspects of the site in hand; and a permit application submitted, it is time to reassess the project. Reevaluate whether the site is truly developable. If no barriers to development have emerged and appropriate technology exists that is procurable and financeable, it is reasonable to begin ramping up analysis and investment in the project.

\section{Action Steps-Stage 1: Money/Financing Details}

1. Obtain an initial rough cost from contractor (in combination with selected technology costs, the infrastructure costs will allow determination of the minimum required power purchase price).

2. Conduct a market assessment to identify potential power buyers at the determined rate floor. Give serious consideration to engaging a power marketing expert at this stage to get a term sheet with indicative values that could be used to obtain development financing, if required.

3. Conduct an operations, maintenance, and replacement analysis to forecast the costs of plant operations and maintenance and a replacement strategy.

4. Identify all available financial incentives available, e.g., RECs.

5. Develop a financing plan with multiple options based on projected power price and financial incentives available. Every developer will have different needs and appropriate 
strategies at this stage; however, give serious consideration to engaging a finance manager - a company or individual that has arranged financing for multiple energy properties. Begin conversations with potential investors.

6. Recognize that, at this stage, engineering is a significant up-front expense, required to initiate permitting.

7. Consider various construction and operations models as part of the financing plan. The following are examples:

- Build, own, operate, transfer

- $\quad$ Build, own, operate

- Lease, build, operate

- Joint venture: Contractor/power buyer or other project contributor becomes part owner of project.

\section{Action Steps-Stage 2: Political/Organizational/License and Permit Details}

1. Continue discovery to identify any insurmountable problems. Engage ALL stakeholders: agencies, NGOs, other river users, and community members — establish/solidify relationships, identify potential problems, and work toward commitment. If you do not have stakeholder commitment at this point, reassess. Although 100\% buy-in is not necessary, it is important that there not be strong opposition. Conduct this stage of work as if you are conducting a public meeting. If your work is completed effectively here, a public meeting should hold no surprises.

2. Consider partnering with a nearby water district, municipality, or other public entity. A partnership of this nature could facilitate a project politically and financially.

3. Conduct enough engineering to initiate serious discussions with contractors. Begin to flesh out contracting options: e.g., collaborative contracting; engineer, procure, construct; and other arrangements to ensure there are no construction issues with the proposed site that will prohibit development. One method that has proven effective is to engage a contractor in the initial work of site analysis, with the option to scale up to full project involvement through a single change order, at which time early project work costs are rolled into final project costs. If at all possible, a geotechnical analysis should be completed at this stage (to minimize geotechnical unknowns and uncertainty and thus risk), as geotechnical challenges (i.e., unexpected developments) can escalate costs quickly. Such challenges can prove especially challenging on a federal site, which in some cases can require a National Environmental Policy Act analysis process just to conduct the geotechnical work. Make it a goal to complete thorough geotechnical work as early as possible.

4. Make an early visit to FERC and the state dam safety office to establish relationships and identify any significant issues. If the option is available, determine the information and documentation necessary to expedite the project through the FERC process. 
5. If you are working at a USACE site, communicate consistently and often, working to facilitate the process with USACE at every opportunity. Request that USACE review preliminary plans.

6. Establish a plan with your power marketer and begin the negotiation process with potential purchasers.

\section{Action Steps-Stage 3: Equipment Details}

Initiate discussions with prospective equipment suppliers and get quotes on proposed key equipment (e.g., turbine-generators and switchgear).

\section{Best Practice Methodology for Site Viability/Feasibility}

- Use an integrated, multi-disciplinary team approach. Engineers, experienced plant operators, finance experts, licensing professionals, contractors, and key subcontractors (e.g., for high-voltage transmission) should be involved in team meetings to maintain a broad perspective on issues.

- Focus on the feasibility of the site for the purposes of approval, as a hydraulically-perfect site with endangered species issues may be difficult to develop. Emphasize feasibility over hydraulic efficiency with a goal of minimizing project costs.

- Focus on the feasibility of the site with a focus on long-term operations: reliability and safety over hydraulic efficiency to keep project costs down.

- Give serious consideration to long-term maintenance in selecting equipment. Hours required for major maintenance may be hours offline. Small, incremental efficiencies gained through using more technologically sophisticated equipment can quickly disappear as a result of maintenance hours offline. Consider the skill level and training of operations staff and work to match the complexity of the equipment to the training and experience level of the staff. Work with suppliers to secure the simplest, most reliable equipment possible.

- As the project plan is developed, identify key go/no go decision points throughout the process leading to construction.

\section{Mid-Phase Development}

\section{Licensing, Permits, and Contracting Arrangements}

Countless projects have been derailed during the permitting process, most of which is handled under the umbrella of the FERC licensing process. One of the most effective ways to facilitate this process is to submit a thorough and complete FERC license application. Surprisingly, many FERC licenses are held up because of incomplete applications. Do not bother to submit the application until it is $100 \%$ complete, as the process is extended every time FERC has to go back to the developer with questions. Successful developers have found it effective to build the license application in the exact same format as it appears in the Code of Federal Regulations Title 18, "Conservation of Power and Water Resources." This makes it easier for FERC licensing staff to review and approve the application. Shortening the FERC licensing process will bring project costs down. 


\section{Action Steps-Licensing and Permits}

1. Request early reviews from agencies to identify any agency issues early in the process.

2. Complete and submit the FERC application and schedule the public meeting as early as possible. If work with ALL stakeholders has been thorough and collaborative, no unexpected issues should arise at the public meeting.

3. Initiate all other relevant permits and approvals: USACE, US Fish and Wildlife Service, the Environmental Protection Agency, state health (water quality) and natural resources agencies. Some of this work will take place in parallel with the FERC process. Note that the USACE 408 Permit process (specific to projects that affect USACE levees or dams) still does not start until the FERC license is issued, which poses a clear and serious scheduling challenge (the hydropower industry is working to get this changed).

4. Recognize that even when the FERC license is granted, permission to construct must be granted by FERC. Permission to construct will not be granted until the developer can document full financing and receipt of all required permits outside the FERC process. This requirement can result in long delays.

\section{Best Practice Methodology for Licensing and Permits}

- Consider engaging a licensing and permitting advisor.

- Develop a project permitting plan.

- Involve all stakeholders (agencies, NGOs, community members) early in the process.

- Hold the public meeting as early as possible after all stakeholders have already been engaged. The ideal scenario is for the public meeting to be merely a formality. If any stakeholder dissent is still a problem, have a clear plan for minimizing the effects or consider returning to project negotiations.

\section{Action Steps-Contracting}

1. Finalize construction arrangements and agreements with the chosen contractor, while maintaining an alternative construction option in the case of contractor issues.
a. Collaborative contracting - construction management through an owner representative
b. Engineer, procure, construction management
c. Engineer, procure, construct
d. Engineer, procure, construct, operate (the contractor carries out operations and maintenance for the first one to two years)
e. Distributed contracting

2. Conduct engineering in collaboration with contractors. Successful projects completed with limited cost overruns have often engaged contractors during early stages of design and engineering. Collaborative contracting has proved to be an effective method of cost control. 


\section{Best Practice Methodology for Contracting Arrangements}

- Give serious consideration to a variety of prospective contracting arrangements. In the last several decades, projects have often been completed through engineer, procure, construct (EPC) contracts. An EPC contract is appealing to finance partners, because one party is ultimately responsible for any issues that arise. Having a single point of responsibility, in theory, limits issues that arise for which there is no clear responsibility. One problem with an EPC contract, however, is that the same issues still arise among subcontractors; they can be difficult to resolve and can just as easily end up in court. At the same time, the EPC arrangement can eliminate many potential cost savings for the owner. Although it requires more developer involvement (e.g., using an owner representative), avoiding an EPC contract can bring project costs down.

- No matter what the construction arrangement, engage contractors, engineers, and operators in this stage of the process to identify and eradicate potential construction and operational issues with a focus on cost control. Experienced plant operators can identify prospective operations issues that engineering teams (who have not had to run plants on a daily basis) can miss. Early collaboration among contractors, engineers, and project operators has proved to be a successful method for containing costs, as each group has separate contributions that can improve and streamline the final project. Collaborative planning eliminates costly change orders and brings project costs down.

\section{Financing}

Completing final financing arrangements hinges upon having the following key items in place:

- PPA

- FERC license (requires engineering to be $80 \%$ complete)

- Land ownership/lease/rights approved

- Water rights in place

- Key permits in place

- Contracting arrangements in place

- Cost-to-build close to finalization

- Business plan

\section{Action Steps-Financing}

Finalize the financing plan. Laying the groundwork for financing started in the early stages of the project. With the assistance of a financial consultant (engaged in the viability/feasibility stage), conduct a final analysis of alternative financing mechanisms. Seriously consider mechanisms other than debt financing. Consider all available options including the following (as applicable).

- US Department of Agriculture Rural Utility Services-Is there any potential for Rural Utility Services involvement (http://www.rurdev.usda.gov/utilities_lp.html)? The location will determine whether that is the case.

- Natural Resources Conservation Services financing

- Municipal collaboration 


\section{o Capacity pre-payment}

o Use the project to offset the use of a significant power-consuming municipal utility, such as a water treatment plant, that may result in a different project development approach such as the following:

- build, own, operate, transfer

- build, own, operate

- lease, build, operate

- joint venture (contractor becomes part owner of project)

\section{Best Practice Methodology for Financing}

- Begin to develop financing partners as early as possible in the project. Although final arrangements often cannot be made until the previous key items are in place, cultivating strong financial partners with a strong interest in the project early in the process is of significant value. The right financer will be familiar with hydropower and will understand that returns from hydropower tend to be stable and reliable-it is a long-term investment. Appropriate investors are willing to value the stability and reliability of returns over seeking a quick profit.

- Consider innovative financing mechanisms such as leasebacks and capacity prepays.

\section{Final Stage Development}

\section{Procurement, Final Design, and Construction Plan}

This final development stage requires the simultaneous management of nearly every aspect of the project. Financing arrangements are likely to be wrapping up, and permits may still be in flux. While these pieces are being wrapped up, the focus at this time is on procuring equipment, finalizing design, and developing a final construction plan. In the design of a plant, simplicity of systems and ruggedness of parts are essential to minimizing operation and maintenance costs. Focus on centralizing control of all aspects, as much as is practical, to allow convenient, rapid inspection and repairs. Consider including plant operations personnel in the design phase of a project to review the plant layout from an operator's perspective. Including the operating staff will help maintain lower operating costs over time. Consider using a separate firm for equipment installation that is specifically devoted to the installation of hydropower equipment

\section{Action Steps}

1. Initiate early and consistent communication among equipment providers and project engineers.

2. Maintain a collaborative process with all project participants in finalizing the construction plan to eliminate costly change orders.

3. Develop a construction plan with all costs embedded into the plan.

4. Prepare a commissioning plan in collaboration with contractors, operating staff, and the equipment installation team. 


\section{Best Practice Methodology for Final Stage}

- Consider various options for procurement, e.g., wrapping procurement into the EPC contract (if used). Owner direct purchase and supply of certain equipment may be worth considering (e.g., a water-to-wire package-turbine/generator/governor)

- Maintain a vigilant focus on cost containment.

- Involve the contractor early—it will pay off at this stage.

- Make the best use of technology when financially feasible, including computer modeling.

- Ensure that the commissioning plan requires and results in delivery of as-built drawings and equipment documentation.

\section{Construction and Quality Control}

\section{Action Steps}

1. Develop a construction plan and manage to the plan.

2. Develop a commission plan to bring the plant on line with a strong focus on documentation for future reference.

\section{Best Practice Methodology for Construction and Quality Control}

- Make the best use of technology for construction and as-built drawings.

- Use LIDAR (light detection and ranging) for as-built drawings (this remote-sensing technology uses a laser and reflected light to create accurate as-built drawings).

- Use independent inspectors.

- Do as much building/packaging of systems in the shop as possible to speed up construction. For example, put control systems/oil systems, and the like on skids to be shipped to the job site and installed.

- Do as much of the testing/checking in the shop as feasible before installation to minimize the time involved in project commissioning.

- Factor in a sufficient shakedown period before instituting operations requirements from the power purchaser. The shakedown period will be used to identify and address bugs throughout the entire plant system.

\section{Operation and Maintenance}

The commissioning of the plant moves the project into the operation and maintenance stage. This involves the day-to-day operation of the project facilities, regularly scheduled maintenance, and eventual refurbishment or replacement of key project components. The ultimate objective of an excellent operations and maintenance program is to maximize plant availability while improving plant efficiency or water-to-power conversion while protecting the life cycle of all necessary 
equipment. A key concept is that energy production and plant management must be maintained with a high level of synergy.

\section{Action Steps}

1. Develop an operation and preventative maintenance approach that forecasts needed replacements. The successful operation of a hydroelectric plant is largely dependent on the organizational (operation-maintenance) plan set up originally for this purpose. This plan will include not only the organization itself but also the necessary tools needed to make it work. The general plan is important because, once established, procedures tend to crystallize and changes become more difficult. This plan needs to consist of a variety of key areas. The following is an overview.

a. Project overview starting at a high level with the operational methods, responsible regulatory agency, owners, equipment type and general objectives of the project.

b. Project detailed description and location including not just the plant but the entire project, such as roads, boat landings, camping areas, and fishing access or platforms.

c. Project history in enough detail to fully understand how the project arrived at the current status and its relationship to the original design or structure. This information will vary dramatically depending on whether it is a rehabilitated project, a new project at an existing dam, or all-new construction,

d. Hydrology and hydraulics

i. An overview of all pertinent data such as watershed characteristics

ii. Historical data with regard to flood events and subsequent details of damage or areas of impact

iii. State or federal regulatory restrictions or conditions

iv. All data points for not only tailwater and headwater levels but also inflows or outflows or gauges in the watershed

v. Civil attributes, including all capability to discharge flows, such as overflow or emergency spillways, and all varied configurations of gates with pertinent discharge capacities

vi. Mechanical attributes showing types and numbers of turbines with discharge capabilities

e. Power production configuration capability

i. Impoundment size and configuration, including storage capacity and level restrictions 
ii. Operational parameters, including allowed flow as well as reservoir level variation with focus on type of operation: run of river, modified peaking, and so on

iii. Capacity and energy components in relationship to value under the power purchase agreement

iv. Generating equipment, showing not only key components such as turbine and generators but also balance of plant, with footprint location and photo of each piece of equipment.

v. Explanation with pertinent documentation of software and equipment for any local control logic, automation, or remote monitoring/control

\section{f. Operations}

i. Listing of all personnel contact information under normal and emergency conditions.

ii. Operator responsibility with complete listing of all inspection forms, logs or procedures (e.g., daily, weekly, monthly, annual)

iii. All state or federal regulatory restrictions, including emergency plans or license articles with specific conditions imposed on operation as well as notification or inspection requirements

g. Maintenance

i. Listing of all equipment, preferably with photos showing location in powerhouse or on project grounds with pertinent nameplate or technical details

ii. Manufacturers’ equipment documentation

iii. Inspection and maintenance requirements for each piece of equipment with appropriate time schedules

iv. Safety features of equipment and project structures

v. Emergency operation guidelines

2. Develop meaningful performance measurements such as plant availability. It is important to identify appropriate performance measures in order to track and validate plant effectiveness over time. Some of the most commonly used measures include plant availability, unscheduled outages versus scheduled outages, total generation, and lost revenue

3. Develop a staffing plan, select and train staff. The size of the organization will depend on the size, capacity, and accessibility of the plant. Details such as number of units, complexity of the station layout, and whether the plant will be operated automatically or 
manually will determine the organization and personnel needed. The size of the organization also depends on the extent to which the plant will be called upon to handle its own maintenance or administrative functions, such as accounting, purchasing, real estate, or legal work. Today, small stations are typically operated by semi-automatic equipment with some supervisory control. Such stations require only periodic visits by an operator, who may handle two or three small stations. Experience has shown two daily visits to the project should be the minimum - the operators need to be on-the-scene observers to ensure a safe, reliable, plant.

Continuing proper training for the operations and maintenance staff in both normal and emergency operation is paramount. Their exposure to and familiarity with the regulatory restrictions or compliance mandates should also be discussed during these ongoing sessions.

4. Engineering support in the operation. In the operation of a project, it is desirable to have engineering talent available and involved that parallels the rest of the organization from top to bottom. This engineering involvement has to be allowed to make the necessary decisions promptly and effectively. Without consistent engineering assistance, regulatory noncompliance, damage to equipment, and operational inefficiency will certainly become an issue. On smaller, individual projects, this support could be a part-time engineer; a standing relationship with an engineering firm; or, as is often the case, the owner, who has the necessary skills or is forced to develop them.

\section{Best Practice Methodology}

- Involve operations staff during design process.

- Have an on-call operation staff who visit the plant on a daily basis.

- Develop and use a disciplined approach to maintenance through a documented maintenance program.

- Provide consistent, ongoing training for operators.

- Ensure engineering support for operations. 


\section{Appendix B}

\section{Authors and Contributors to Report}

\author{
Lead Authors \\ Norm Bishop, P.E. \\ Senior Vice President \\ Knight Pièsold \\ Deborah Linke \\ Executive Director \\ Hydro Research Foundation

\section{Editor} \\ Carl Vansant \\ Principal Partner \\ HCI Partners, Inc.

\section{Contributing Authors} \\ Charles Alsberg \\ Chairman \\ America’s Energy Holding Company
}

Jay Anders

Hydropower and Hydraulic Structures

Black \& Veatch

Ali Grovue

Chief Operating Officer

Instream Energy Systems

Director

BC Sustainable Energy Association

Sarah Hill-Nelson

Co-Chair Small Hydro Committee

National Hydropower Association

Owner

The Bowersock Mills \& Power Company

Kurt Johnson

Telluride Energy
Brennan Smith, PhD

Program Director

Water Power Research and Development

Oak Ridge National Laboratory

David J. Youlen, P.E.

Executive Vice President for Development

Eagle Creek Renewable Energy

Kevin R. Young

Director of Energy Licensing and

Compliance Services

Alden Research Laboratory, Inc.

\section{Contributors}

Sharon Atkin

Percheron Power, LLC

Brett Bauer

Canyon Hydro

Kearon Bennett

Ottawa Engineering

IEA Small Hydropower Annex

David H. Brown Kinlock

Shaker Landing Hydro Associates, Inc.

James Gordon

HydroHelp-OEL Hydrosys

Jeanne Hilsinger

Mavel, a.s.

Harold Linke

Linke Consulting 
Brian Murtha

Voith Hydro Inc.

Michael Pulskamp

Bureau of Reclamation

Paul Roos

AMJET Turbine Systems, LLC
Brian Robin

MJ2 Technologies

VLH Turbines

Brian Shenk

US Army Corps of Engineers

Brenna Vaughn

Hydro Research Foundation 